\title{
ENETS Consensus Guidelines for the Management of Patients with Digestive Neuroendocrine Neoplasms: Functional Pancreatic Endocrine Tumor Syndromes
}

\author{
Robert T. Jensen ${ }^{a}$ Guillaume Cadiot ${ }^{b}$ Maria L. Brandic Wouter W. de Herder ${ }^{d}$ \\ Gregory Kaltsas $^{\text {e }}$ Paul Komminoth ${ }^{f}$ Jean-Yves Scoazec ${ }^{g}$ Ramon Salazar $^{\text {h }}$ \\ Alain Sauvanet ${ }^{i}$ Reza Kianmanesh ${ }^{j}$ \\ all other Barcelona Consensus Conference participants ${ }^{1}$ \\ a Digestive Diseases Branch, NIH, Bethesda, Md., USA; b Service d'Hépato-Gastroentérologie, CHU de Reims, \\ Hôpital Robert Debré, Reims, France; ' University of Florence, Florence, Italy; ${ }^{\mathrm{d}}$ Department of Endocrinology, \\ Erasmus MC University, Rotterdam, The Netherlands; ' Department of Pathophysiology, National University of \\ Athens, Athens, Greece; Institute of Pathology, Stadtspital Triemli, Zurich, Switzerland; ${ }^{\mathrm{f}}$ Hospices Civils de Lyon, \\ Hôpital Edouard Herriot Service Central d'Anatomie et Cytologie Pathologiques, Lyon, France; ${ }^{\text {h}}$ Department \\ of Oncology, Institut Català d'Oncologia (IDIBELL), Barcelona, Spain; 'Hospices Civils de Lyon, Hôpital Edouard \\ Herriot Service Central d'Anatomie et Cytologie Pathologiques, Lyon, and ${ }^{\mathrm{j} D e p a r t m e n t}$ of Surgery, Louis-Mourier \\ University Hospital, Colombes, France
}

\section{Introduction}

Pancreatic endocrine tumors (p-NETs) include both pancreatic neuroendocrine tumors (p-NETs) associated with a functional syndrome (functional p-NETs) or those associated with no distinct clinical syndrome (non-functional p-NETs) [1-4]. Non-functional p-NETs frequently secrete pancreatic polypeptide, chromogranin A, neuron-specific enolase, human chorionic gonadotrophin subunits, calcitonin, neurotensin or other peptides, but they do not usually produce specific symptoms and thus are considered clinically to be non-functional tumors $[2$, $3,5-7]$. Only the functional p-NETs will be considered in this section. The two most common functional p-NETs (gastrinomas, insulinomas) are considered separately, whereas the other well-described and possible rare functional p-NETs are considered together as a group called rare functional p-NETs (RFTs) (table 1) [1-4].

\section{KARGER}

Fax +41613061234 E-Mail karger@karger.ch www.karger.com (c) 2012 S. Karger AG, Basel

0028-3835/12/0952-0098\$38.00/0

Accessible online at:

www.karger.com/nen
Gastrinomas are neuroendocrine neoplasms, usually located in the duodenum or pancreas, that secrete gastrin and cause a clinical syndrome known as Zollinger-Ellison syndrome (ZES). ZES is characterized by gastric acid hypersecretion resulting in severe peptic disease (peptic ulcer disease (PUD), gastroesophageal reflux disease (GERD)) [8-10]. In this section, ZES due to both duodenal and pancreatic gastrinomas will be covered together because clinically they are similar $[8,10]$. Specific points related to gastrinomas associated with the genetic syndrome of Multiple Endocrine Neoplasia type 1 (MEN1) (25\% of cases) will also be mentioned [11, 12].

Insulinomas are neuroendocrine neoplasms located in the pancreas that secrete insulin, which causes a distinct syndrome characterized by symptoms due to hypoglyce-

1 See list at the end of the paper.
Dr. R.T. Jensen

Digestive Diseases Branch, Cell Biology Section

National Institutes of Health

Building 10, Room 9C-103, Bethesda, MD 20892 (USA)

Tel. +1 301496 4201, E-Mail robertj@bdg10.niddk.nih.gov 
mia $[2,13-15]$. The symptoms are typically associated with fasting and the majority of patients have symptoms secondary to hypoglycemic central nervous system (CNS) effects (headaches, confusion, visual disturbances, etc.) or due to catecholamine excess secondary to hypoglycemia (sweating, tremor, palpitations, etc.) [2, 3, 13-15].

RFTs can occur in the pancreas or in other locations (VIPomas, somatostatinomas, GRHomas, ACTHomas, p-NETs causing carcinoid syndrome or hypercalcemia (PTHrp-omas)) (table 1) [1-5, 7]. Each of the established RFT syndromes is associated with a distinct clinical syndrome reflecting the actions of the ectopically secreted hormone. Other RFTs are listed as causing a possible specific syndrome either because there are too few cases or there is disagreement about whether the described features are actually a distinct syndrome (table 1) [1$5,7]$.

\section{Epidemiology and Clinicopathological Features of Functional p-NETs}

\section{Gastrinomas: Minimal Consensus Statement on Epidemiology and Clinicopathological Features}

Gastrinomas - Epidemiology and Site of Origin - Specific (table 1) $[1-3,8,9,16,17]$

The incidence of gastrinomas is $0.5-2 /$ million population/ year. They are the most common functional, malignant $\mathrm{p}$-NET syndrome and comprise up to $30 \%$ of these $[1,2,8,9]$. Duodenal tumors, which were originally thought to be uncommon (i.e. $<20 \%$ ), now make up $50-88 \%$ of gastrinomas in sporadic ZES patients and $70-100 \%$ of gastrinomas in MEN1/ZES patients [8, $16,17]$ In rare cases, gastrinomas occur in other non-pancreatic, non-duodenal abdominal (stomach, liver, bile duct, ovary) (5$15 \%$ ) and extra-abdominal (heart, small cell lung cancer) locations $[8,16-18]$. The exact site of origin of sporadic gastrinomas is unknown, however, in MEN1/ZES patients the duodenal gastrinomas (which occur in 70-100\%) originate from diffuse gastrin cell proliferations $[16,19]$.

Gastrinomas - Clinicopathological Features - Specific

Similar to other gastroenteropancreatic neuroendocrine neoplasms, gastrinomas can be classified both using the current WHO classification system with TNM classification and grading [20] based on the ENETS TNM and grading [21], which both proved to have prognostic significance [3,22-30]. According to WHO 2010, gastrinomas are NET G1-G2, usually $>1 \mathrm{~cm}$, showing local invasion and/or proximal lymph node metastases $[8$, $16,17,20,31]$. Liver metastases (LM) occur much more frequently with pancreatic gastrinomas (22-35\%) than duodenal gastrinomas $(0-10 \%)[8,17,18,31]$. Pancreatic gastrinomas are generally large in size (mean $3.8 \mathrm{~cm}, 6 \%<1 \mathrm{~cm}$ ), whereas duodenal gastrinomas are usually small (mean $0.93 \mathrm{~cm}, 77 \%<1 \mathrm{~cm}$ ) $[8$, 31-33]. While the pancreatic gastrinomas may occur in any por- tion of the pancreas, duodenal gastrinomas are predominantly found in the first part of the duodenum including the bulb $[8$, $17,18,31]$. At surgery, $70-85 \%$ of gastrinomas are found in the right upper quadrant (duodenal and pancreatic head area), the so-called 'gastrinoma triangle' $[8,17,18,34]$.

MEN1 is an autosomal-dominant syndrome that is present in $20-30 \%$ of patients with ZES $[11,12]$. In these patients duodenal tumors are usually (70-100\%) responsible for the ZES. The duodenal tumors are almost always multiple $[11,16,17,35,36]$. Histologically, most gastrinomas are well differentiated and show a trabecular and pseudoglandular pattern. Their proliferative activity (i.e. the Ki67 index) varies between 2 and $10 \%$, but is mostly close to $2 \%$. Immunohistochemically, almost all gastrinomas stain for gastrin $[8,17]$.

\section{Insulinomas: Minimal Consensus Statement on Epidemiology and Clinicopathological Features (table 1)}

Insulinomas: Minimal Consensus Statement on

Epidemiology and Clinicopathological Features - Specific

(table 1)

Insulinomas are the most common functioning neuroendocrine tumor of the pancreas, with an estimated incidence of 1-3/ million population/year [1-3, 13-15]. Less than $10 \%$ are malignant. There is an age-specific incidence peak in the fifth decade of life and the incidence is slightly higher in women than in men. Approximately $10 \%$ are multiple, and approximately $5 \%$ are associated with the MEN1 syndrome $[1,2,11,13,13,15,26]$. Isolated sporadic insulinomas are generally cured by pancreatic resection $[13-15,26]$. A multidisciplinary team approach is required $[13-15,26]$.

\section{Rare Functioning Tumors (table 1): Minimal Consensus Statements on Epidemiology and Clinicopathological Features [1-5, 37, 38]}

Rare Functioning Tumors (table 1): Minimal Consensus Statements on Epidemiology and Clinicopathological

Features - Specific

RFTs include the established RFT syndromes: glucagonomas, VIPomas, somatostatinomas, GRHomas, ACTHomas, p-NETs causing carcinoid syndrome or hypercalcemia (PTHrp-omas). RFTs also include five possible RFT syndromes: $p$-NETs secreting calcitonin, renin, luteinizing hormone, erythropoietin and insulin-like growth factor II (table 1) $[1-5,7,37,38]$ whose status is unclear whether they represent a specific syndrome because of the small numbers of cases (table 1) $[1-3,5,7,37,38]$. RFTs represent less than $10 \%$ of all p-NETs $[2,5]$. The majority of patients with RFTs of the pancreas present with metastatic disease (40-90\%) in the liver. Somatostatinomas can occur in the pancreas or upper small intestine, however, the duodenal somatostatinomas are rarely associated with a functional clinical syndrome (the somatostatinoma syndrome) (table 1) [2, 37, 39]. In addition to somatostatinomas, a number of the other RFTs occur in extrapancreatic locations also (table 1). Most RFTs are 
Table 1. Functional pancreatic endocrine tumor (PET) syndromes

\begin{tabular}{|c|c|c|c|c|c|c|}
\hline Name & $\begin{array}{l}\text { Biologically } \\
\text { active peptide(s) } \\
\text { secreted }\end{array}$ & $\begin{array}{l}\text { Incidence (new } \\
\text { cases } / 10^{6} \text { popu- } \\
\text { lation/year) }\end{array}$ & Tumor location & $\begin{array}{l}\text { Malig- } \\
\text { nant } \\
\%\end{array}$ & $\begin{array}{l}\text { Associated } \\
\text { with } \\
\text { MEN-1, \% }\end{array}$ & Main symptoms/signs \\
\hline \multicolumn{7}{|c|}{ A. Most common functional PET syndromes } \\
\hline Insulinoma & insulin & $1-3$ & pancreas $(>99 \%)$ & $<10$ & $4-5$ & hypoglycemic symptoms (100\%) \\
\hline $\begin{array}{l}\text { Zollinger-Ellison } \\
\text { syndrome }\end{array}$ & gastrin & $0.5-2$ & $\begin{array}{l}\text { duodenum }(70 \%) \\
\text { pancreas }(25 \%) \\
\text { other sites }(5 \%)\end{array}$ & $60-90$ & $20-25$ & $\begin{array}{l}\text { pain }(79-100 \%) ; \\
\text { diarrhea }(30-75 \%) ; \\
\text { esophageal symptoms }(31-56 \%)\end{array}$ \\
\hline \multicolumn{7}{|c|}{ B. Established rare functional PET syndromes (RFTs) } \\
\hline $\begin{array}{l}\text { VIPoma (Verner-Morrison } \\
\text { syndrome, pancreatic } \\
\text { cholera, WDHA) }\end{array}$ & $\begin{array}{l}\text { vasoactive } \\
\text { intestinal peptide }\end{array}$ & $0.05-0.2$ & $\begin{array}{l}\text { pancreas ( } 90 \% \text {, adult }) ; \\
\text { other }(10 \%, \text { neural, } \\
\text { adrenal, periganglionic) }\end{array}$ & $40-70$ & 6 & $\begin{array}{l}\text { diarrhea }(90-100 \%) \text {; } \\
\text { hypokalemic }(80-100 \%) \text {; } \\
\text { dehydration }(83 \%)\end{array}$ \\
\hline Glucagonoma & glucagon & $0.01-0.1$ & pancreas $(100 \%)$ & $50-80$ & $1-20$ & $\begin{array}{l}\text { rash }(67-90 \%) \\
\text { glucose intolerance }(38-87 \%) \\
\text { weight loss }(66-96 \%)\end{array}$ \\
\hline Somatostatinoma & somatostatin & rare & $\begin{array}{l}\text { pancreas (55\%); } \\
\text { duodenum/jejunum (44\%) }\end{array}$ & $>70$ & 45 & $\begin{array}{l}\text { diabetes mellitus (63-90\%); } \\
\text { cholelithiases }(65-90 \%) ; \\
\text { diarrhea }(35-90 \%)\end{array}$ \\
\hline GRHoma & $\begin{array}{l}\text { growth hormone- } \\
\text { releasing hormone }\end{array}$ & unknown & $\begin{array}{l}\text { pancreas }(30 \%) \text {; } \\
\text { lung }(54 \%) ; \text { jejunum }(7 \%) \text {; } \\
\text { other }(13 \%)\end{array}$ & $>60$ & 16 & acromegaly (100\%) \\
\hline ACTHoma & $\mathrm{ACTH}$ & rare & $\begin{array}{l}\text { pancreas ( } 4-16 \% \text { all } \\
\text { ectopic Cushing's) }\end{array}$ & $>95$ & rare & Cushing's syndrome (100\%) \\
\hline $\begin{array}{l}\text { PET causing carcinoid } \\
\text { syndrome }\end{array}$ & $\begin{array}{l}\text { serotonin? } \\
\text { tachykinins }\end{array}$ & $\begin{array}{l}\text { rare } \\
(43 \text { cases })\end{array}$ & $\begin{array}{l}\text { pancreas }(<1 \% \text { all } \\
\text { carcinoids })\end{array}$ & $60-88$ & rare & $\begin{array}{l}\text { same as carcinoid syndrome } \\
\text { above }\end{array}$ \\
\hline $\begin{array}{l}\text { PET causing hypercalcemia } \\
\text { (PTHrp-oma) }\end{array}$ & $\begin{array}{l}\text { PTHrp; } \\
\text { others unknown }\end{array}$ & rare & $\begin{array}{l}\text { pancreas (rare cause of } \\
\text { hypercalcemia) }\end{array}$ & 84 & rare & $\begin{array}{l}\text { abdominal pain due to hepatic } \\
\text { metastases, symptoms due to } \\
\text { hypercalcemia }\end{array}$ \\
\hline \multicolumn{7}{|c|}{ Possible rare functional PET syndromes } \\
\hline PET secreting calcitonin & calcitonin & rare & $\begin{array}{l}\text { pancreas (rare cause of } \\
\text { hypercalcitonemia) }\end{array}$ & $>80$ & 16 & diarrhea $(50 \%)$ \\
\hline PET secreting renin & renin & rare & pancreas & unknown & no & hypertension \\
\hline $\begin{array}{l}\text { PET secreting luteinizing } \\
\text { hormone }\end{array}$ & $\begin{array}{l}\text { luteinizing } \\
\text { hormone }\end{array}$ & rare & pancreas & unknown & no & $\begin{array}{l}\text { anovulation, virilization } \\
\text { (female): reduced libido (male) }\end{array}$ \\
\hline PET secreting erythropoietin & erythropoietin & rare & pancreas & 100 & no & polycythemia \\
\hline PET secreting IF-II & $\begin{array}{l}\text { insulin-like } \\
\text { growth factor II }\end{array}$ & rare & pancreas & unknown & no & hypoglycemia \\
\hline
\end{tabular}

diagnosed as WHO group 2. Not enough data in the literature is currently available to give accurate estimates on survival. The average age at diagnosis is estimated to be $50-55$ years, with equal gender distribution. Patients with malignant tumors may present with mixed syndromes or tumors may change clinically over time. The most frequent familial condition associated with RFT is MEN1, with glucagonomas occurring in 3\% of MEN1 patients, VIPomas in 3\%, GRHomas, somatostatinomas in $<1 \%$ $[11,40]$. Somatostatinomas (especially periampullary) are seen in up to $10 \%$ of patients with von Recklinghausen's disease (neurofibromatosis 1) but in almost all cases they are not associated with a functional syndrome (somatostatinoma syndrome) $[5,11$, 39].

\section{Prognosis and Survival in Functional p-NETs and MEN1}

\section{Minimal Consensus Statement on Prognosis and Survival in Functional p-NETs and MEN1}

Gastrinomas: Minimal Consensus Statement on Prognosis and Survival - Specific [8, 9, 18, 41, 42]

Prospective studies show in approximately $25 \%$ of patients with sporadic ZES and in 15\% with MEN1/ZES the gastrinomas demonstrate aggressive growth $[8,9,31,41,43]$. Approximately $30-40 \%$ of gastrinomas are associated with LM [44]. At diagnosis, $5-10 \%$ of duodenal gastrinomas and $20-25 \%$ of pancreatic gastrinomas are associated with LM $[8,9,31,41]$. LM are the 
most important prognostic factor, the 10 -year survival being $90-100 \%$ without LM and 10-20\% with LM [8, 9, 31, 41, 42]. Poor prognostic factors besides LM include: inadequate control of gastric acid hypersecretion; presence of lymph node metastases $(\mathrm{p}=0.03)$; female gender ( $\mathrm{p}<0.001)$; absence of MEN1 $(\mathrm{p}<$ $0.001)$; short disease history from onset to diagnosis $(\mathrm{p}<0.001)$; markedly increased fasting gastrin levels $(\mathrm{p}<0.001)$; presence of a large primary tumor $(1-3 \mathrm{~cm})(\mathrm{p}<0.001)$; a pancreatic primary gastrinoma ( $\mathrm{p}<0.001)$; development of ectopic Cushing's syndrome or bone metastases $(\mathrm{p}<0.001)$; the presence of various flow cytometric features, advanced TNM classification status; molecular features (high HER2/neu gene expression $(\mathrm{p}=0.03$ ), high 1q LOH, increased EGF of IGF1 receptor expression), or histological features including angioinvasion, perineural invasion, $>2$ mitoses per $20 \mathrm{HPF}, \mathrm{Ki} 67$ index $>2$, poor differentiation $[8,9,18,25,31,41,42,45-48]$.

Insulinomas: Minimal Consensus Statement on Prognosis and Survival - Specific

Greater than $90-95 \%$ of insulinomas are benign at presentation, and $95-100 \%$ of these can be surgically cured $[1,2,13-15$, $26,49]$. The $<10 \%$ with LM have a median survival of less than 2 years $[13,15,50]$. Tumor size $\geq 2 \mathrm{~cm}, \mathrm{Ki} 67>2 \%$ and various molecular features (chromosomal instability; chromosomal loss of $3 p$ or $6 q$; chromosomal gain on $7 \mathrm{q}, 12 \mathrm{q}$ or $14 \mathrm{q}$ ) all are predictors of metastatic disease, which is associated with decreased survival [51].

RFTs: Minimal Consensus Statement on Prognosis and Survival - Specific

Most RFTs present with metastatic disease and their 5-year survival is increasingly determined by the growth of the tumor, rather than the hormone excess state. Five-year survival for the group with advanced disease is $29-45 \%[1,2,4,5]$. All of the survival/prognostic data on the individual RFTs comes from retrospective studies and in recent studies their results are often included in non-insulinoma/non-gastrinoma series that include non-functional p-NETs. These studies demonstrate tumor Ki67 $\geq 2 \%$, presence of LM, presence of cytokeratin-19 staining and various molecular features (chromosome 7 p gain), chromosomal instability) were associated with a poor prognosis $[2,42,51]$.

MEN1: Minimal Consensus Statement on Prognosis and Survival - Specific

The prognostic significance of MEN1 in patients with pNETs is not entirely clear. Some studies in patients with gastrinomas suggest these patients have a better prognosis, even though the gastrinomas are almost always multiple [8, 31, 41, 43]. However, because the patients present at an earlier age, this could affect the survival results $[31,41]$. Patients with MEN1 frequently have multiple insulinomas, however, these are usually cured surgically $[11,52]$. There are no comparative studies on survival in MEN1 patients with insulinomas compared to sporadic cases. In older studies, survival was primarily determined by the development and adequacy of treatment of ZES, development of renal failure from inadequately treated hyperparathyroidism and the malignant nature of the p-NETs $[11,53]$. With the ability to treat both the ZES and the hyperparathyroidism, recent studies show in patients with MEN1, the natural history of the p-NET increasingly becoming a determinant of sur- vival [11]. In the French registry that included 758 patients with MEN1, thymic tumors and duodenopancreatic tumors, including non-secreting pancreatic tumors but not insulinomas, increased the risk of death $[53,54]$. Thymic carcinoid occur primarily in males $(>90 \%)$ and are a particularly aggressive tumor causing not only local encasement of vital structures in the mediastinum, but also the early development of distal metastases to liver and bone $[11,53,55]$.

\section{Clinical Presentation of Functional p-NETs}

\author{
Minimal Consensus Statement on Clinical \\ Presentation of Functional p-NETs
}

Gastrinomas: Minimal Consensus Statement on Clinical

Presentation - Specific (table 1) [3, 8-10, 12, 32, 56-59]

The mean age of patients with sporadic gastrinomas is $48-55$ years; $54-56 \%$ are males, and the mean delay in diagnosis from the onset of symptoms is 5.2 years. All of the symptoms except those late in the disease course are due to gastric acid hypersecretion. The majority of ZES patients present with a single duodenal ulcer, peptic symptoms, GERD symptoms or ulcer complications and diarrhea. Multiple ulcers or ulcers in unusual locations are a less frequent presenting feature than in the past $[3$, $8-10,12,32,56-59]$. With the widespread use of gastric antisecretory drugs, particularly proton pump inhibitors (PPIs), symptoms may be masked and the diagnosis most often suggested by the long history of PUD/GERD symptoms or their recurrence after treatment $[3,32,57,59,60]$. Abdominal pain primarily due to PUD or GERD occurs in $75-98 \%$ of the cases, diarrhea in $30-73 \%$, heartburn in $44-56 \%$, bleeding in $44-75 \%$, nausea/vomiting in $12-30 \%$ and weight loss in $7-53 \%[8,10,57]$. At presentation, $>97 \%$ of patients have an elevated fasting serum gastrin (FSG) level, 87-90\% have marked gastric acid hypersecretion (basal acid output $>15 \mathrm{mEq} / \mathrm{h}$ ) and $100 \%$ have a gastric acid $\mathrm{pH}<2$ [61]. Patients with MEN1 with ZES (20-30\%) present at an earlier age (mean 32-35 years) than patients without MEN1 (i.e. sporadic disease) $[11,12]$. In up to $45 \%$ of MEN1/ZES patients, the symptoms of ZES precede those of hyperparathyroidism, and they can be the initial symptoms these patients present with $[11,12,62]$. However, almost all MEN1/ZES patients have hyperparathyroidism at the time the ZES is diagnosed, although in many patients it can be asymptomatic and mild and therefore can be easily missed if ionized calcium and serum parathormone levels are not performed $[11,12]$ or an oral calcium challenge test [63]. Of all MEN1/ZES patients, 25\% lack a family history of MEN1, supporting the need to screen all ZES patients for MEN1 [11, 12].

Insulinomas: Minimal Consensus Statement on Clinical Presentation - Specific (table 1)

Insulinomas characteristically present between ages 40 and 45 years, $60 \%$ occur in females, and the symptoms are due to hypoglycemia $[1-3,13-15,50]$. The majority of symptoms are related to the effects of hypoglycemia on the CNS and include confusion, visual disturbances, headaches, behavioral changes, or coma. Most patients also have symptoms due to adrenergic 
stimulation secondary to the hypoglycemia, which include sweating, tremor, palpitations and irritability. The mean duration of symptoms at diagnosis is 3 years and a recent increase in body weight is present in the majority of patients $[1-3,13-15$, 50].

Rare Functioning Tumors: Minimal Consensus Statement on Clinical Presentation - Specific (table 1)

RFTs characteristically present with the symptoms of the specific hormone excess state (table 1), and in most cases present late in the disease course when advanced disease is already present $[2,4,5]$. In a small percentage of patients with a functional $\mathrm{p}$-NET, a second functional syndrome may develop over time $[64,65]$.

\section{Diagnosis of Functional p-NETs and MEN1}

\section{Diagnosis of Functional p-NETs - General}

The diagnosis of all functional $\mathrm{p}$-NETs requires the demonstration of an inappropriate elevation of the appropriate, specific serum hormonal marker (i.e. gastrin in ZES, insulin in insulinomas, etc.) combined with clinical/laboratory evidence of oversecretion of the appropriate hormone (such as gastric acid hypersecretion in ZES, hypoglycemia in insulinomas, etc.) (table 1) [1$3,57,66]$. The diagnosis of functional p-NET requires clinical evidence of hormonal overexpression (table 1) and is not based only on immunohistochemical results $[1-3,57,66]$.

\section{Diagnosis of ZES - General}

While the diagnosis of ZES generally requires the demonstration of an inappropriate elevation of FSG by demonstrating hypergastrinemia in the presence of hyperchlorhydria or an acidic $\mathrm{pH}$ (preferably $\leq 2$ ), in most cases today the first study done today is the FSG determination $[2,8,32,57,60,66,67]$. The FSG alone is not adequate to make the diagnosis of ZES, because hypergastrinemia can be caused by hypochlorhydria/achlorhydria (chronic atrophic fundus gastritis, often associated with pernicious anemia) as well as other disorders causing hypergastrinemia with hyperchlorhydria besides ZES (Helicobacter pylori infection, gastric outlet obstruction, renal failure, antral G-cell syndromes, short bowel syndrome, retained antrum) $[2,8,32,57,60,66,67]$. No level of FSG alone can distinguish ZES from that seen in achlorhydric states. A recent study [68] demonstrates that it is particularly important that a known, reliable assay be used to determine the fasting gastrin levels. In this study [68] of 12 available gastrin assays examined (7 RIAs, 5 ELISAs), only 5 of the 12 kits accurately measured plasma gastrin concentrations with the others either over- or underreporting the value from the true value [68].

Recent data show that the widespread use of PPIs is making the diagnosis of ZES more difficult and delaying the diagnosis $[2,8,32,5759,60,66,67]$. This is occurring with PPIs because they are potent inhibitors of acid secretion with a long duration of action (i.e. up to 1 week), which has two effects that can lead to misdiagnosis of ZES. First, this results in hypergastrinemia in patients without ZES frequently with peptic symptom history thus mimicking ZES $[2,8,32,57,59,60,66,67]$. This means the PPI needs to be stopped to make the proper diagnosis. However, it can be difficult to stop the drug in some patients, especially those with severe GERD and must be done carefully as discussed below in the specific recommendations for ZES diagnosis. Second, the potent inhibition of acid secretion results in control of symptoms in most ZES patients with conventional doses used in idiopathic peptic disease, in contrast to $\mathrm{H}_{2}$ blockers where conventional doses were frequently not adequate. The result is that PPIs mask the diagnosis of ZES by controlling the symptoms in most patients and that break through symptoms which may lead to a suspicion of ZES and are frequently seen with $\mathrm{H}_{2}$ blockers, are infrequent with PPIs [2, 8, 32, 57, 59, 60, 66, 67].

Patients with ZES with PUD have H. pylori infection in $24-48 \%$ in contrast to patients with idiopathic peptic disease who have $H$. pylori in $>90 \%$. Therefore, lack of $H$. pylori should lead to a suspicion of ZES in a patient with recurrent PUD not taking gastrotoxic drugs [8, 57, 69].

\section{Minimal Consensus Statement on Diagnosis with or without MEN1 - Specific ZES}

Suspect ZES Diagnosis [3, 8, 10, 57, 60, 66, 67]

ZES should be suspected if: recurrent, severe or familial PUD is present; PUD without $H$. pylori or other risk factors (NSAIDs, aspirin) is present; PUD associated with severe GERD is present; PUD resistant to treatment or associated with complications (perforation, penetration, bleeding) is present; PUD occurs with endocrinopathies or diarrhea; PUD occurring with prominent gastric folds at endoscopy (present $-92 \%$ of ZES patients), or with hypercalcemia or hypergastrinemia $[3,8,10,57,60,66]$. It should be sought for in all patients with MEN1 [8, 11]. ZES should also be suspected in PUD patients in whom diarrhea promptly resolved with treatment with PPIs.

ZES Diagnosis: Biochemistry/Laboratory Studies

Whereas the initial study usually performed to support the clinical suspicion of ZES is a FSG level, which is an excellent screening test because it is elevated in $>98 \%$ of all ZES patients, it alone does not establish the diagnosis because of the many other causes of hypergastrinemia $[2,32,58,60,66,67,70]$. The 
fasting gastrin assay should be performed by a known, reliable laboratory [68]. To establish the diagnosis of ZES, FSG and gastric $\mathrm{pH}$ should be determined (following interruption of PPI for at least 1 week with $\mathrm{H}_{2}$ blocker coverage, if possible). If FSG levels are $>10$-fold elevated and gastric $\mathrm{pH}<2$, the diagnosis of ZES can be made, because the possibility of retained gastric antrum can usually be eliminated by history $[2,8,57,58,66]$. Sixty percent of ZES patients do not have very elevated FSG levels $(<10$ fold), and they are in the range that is frequently seen with other diagnoses, including with PPI treatment in non-ZES patients ( $<10$-fold elevated) $[2,32,58,60,66,67,70]$. Many centers do not have the capability of measuring gastric acid secretory rates, however, gastric $\mathrm{pH}$ can be initially measured and a method to perform this at endoscopy has recently been described which may facilitate measurement [71]. If FSG is $<10$-fold elevated and gastric $\mathrm{pH}<2$, then a secretin test and basal acid output (BAO) should be performed. Also, if repeated FSG are performed on different days, $<0.5 \%$ of ZES patients will have all normal values. If a $\mathrm{BAO}$ is performed, $>85 \%$ of patients without previous gastric acid-reducing surgery will have a value $>15 \mathrm{mEq} / \mathrm{h}$ [61]. The criterion for a positive secretin test ( $2 \mathrm{U} / \mathrm{kg}$ rapid infusion) is a $>120$ $\mathrm{pg} / \mathrm{ml}$ increase over the basal FSG, which has a sensitivity of $94 \%$ and a specificity of $100 \%$ [72]. A second way to perform the secretin test has been described using a 1-hour infusion of $3 \mathrm{U} / \mathrm{kg}$ secretin with assessment of acid output and serum gastrin levels [73]. This method has been shown to be very effective with thresholds of $99 \%$ specificity for gastrin levels and acid outputs, but it necessitates the measurement of gastric acid outputs for at least $2 \mathrm{~h}$ and therefore is now less frequently used. Calcium stimulation of gastrin release can also be used to diagnose ZES, but because of its lower sensitivity, specificity and higher side-effect profile, it is now rarely used, except in situations where secretin is not available or the diagnosis of ZES is strongly suspected, but the secretin test is negative $[57,72,74,75]$. PPIs can complicate the diagnosis of ZES because they can cause elevations of FSG in patients without ZES, can lead to false positive secretin tests [76] and can also mask the symptoms of a patient with ZES [3, $32,57,59,60,77]$. PPIs presence can delay the diagnosis of ZES as discussed above. Because of this it is generally not possible to diagnose ZES while a patient is taking PPIs. Therefore to make the diagnosis of ZES, patients are usually switched to $\mathrm{H}_{2}$ receptor antagonists to replace the PPI for at least 1 week. This needs to be performed with caution because some patients will require high, frequent doses, and because stopping PPI can cause complications due to acid hypersecretion in ZES patients (ulcer bleeding, diarrhea with dehydration or hypokalemia) [222]. Therefore, it is best performed by a specialty unit experienced in diagnosing ZES.

The diagnosis of ZES in patients with MEN1 has a number of unusual features and is discussed below in the MEN1 section.

\section{Minimal Consensus Statement on Diagnosis in a Patient with ZES, Insulinomas or RFTs - Specific MEN1}

ZES: Suspect MEN1 [11, 12]

The presence of MEN1 should be particularly sought in patients with ZES because $20-25 \%$ have MEN1 and the patient may present with symptomatic ZES only $[11,12,62]$. In a patient with
ZES, MEN1 should be suspected if there is a family or personal history of endocrinopathies or familial history of recurrent peptic disease; other endocrinopathies are found during the evaluation; there is a history of renal colic or nephrolithiases; history of hypercalcemia or p-NET syndromes, or if multiple p-NETs/ duodenal NETs are present. Furthermore, if carcinoid tumors of the thymus, lung or stomach (type 2) are found, MEN1 should be suspected because these are rarely present in sporadic ZES, but are much more frequent with MEN1 $[12,53,55,78,79]$.

Insulinomas, RFTs: Suspect MEN1 [11]

MEN1 should be suspected in a patient with insulinomas with a personal or family history of any endocrinopathy, especially hyperparathyroidism; a concomitant gastrinoma or other RFT is present or develops with time; a non-functional p-NET is present; or if there are multiple insulinomas or recurrent disease occurs after resection.

Biochemistry/Laboratory Studies to Diagnose MEN1 in a

Patient with a p-NET

Because of the frequency of MEN1 in ZES (20-25\%) and because up to $40 \%$ of MEN1/ZES patients have no family history [10-12], all patients with ZES should have biochemical studies for MEN1. Serum parathormone levels (preferably an intact molecule assay - IRMA), ionized calcium levels and prolactin levels should be performed when initially seen and during yearly follow-up. Ionized calcium levels are much more sensitive than a total calcium- or albumin-corrected calcium determination [11, 12, 63]. In some cases, an oral tolerance calcium test might be performed [63]. ZES can be difficult to diagnose in MEN1 patients after a parathyroidectomy, because if successful, the serum calcium can return to the normal range as well as the serum gastrin, and the secretin test can become negative, masking the presence of the gastrinoma [11, 12, 80-83]. Furthermore, an effective parathyroidectomy can result in a marked decrease in acid secretory rates [80], further masking the presence of ZES and making the diagnosis more difficult.

Genetic Study for MEN1 and Other Inherited Syndromes Associated with p-NETs

If the family history is positive for MEN1, suspicious clinical or laboratory data for MEN1 are found or multiple tumors are present raising the possibility of MEN1, then MEN1 genetic testing should be considered. Genetic testing for MEN1 should include sequencing of the entire gene and its splice variants. If genetic testing is considered, genetic counseling should be performed, prior to testing $[11,84,85]$.

If clinical features suggest von Hippel-Lindau disease (VHL), tuberous sclerosis or NF-1, appropriate gene testing should be considered after genetic counseling [11].

\section{Diagnosis of Insulinomas - General}

\section{Suspect Insulinoma Diagnosis}

Hypoglycemic symptoms can be grouped into those resulting from neuroglycopenia (commonly including headache, diplopia, blurred vision, confusion, dizziness, abnormal behavior, lethargy, amnesia, whereas, rarely, hypoglycemia may result in seizures and coma) and those resulting from the autonomic ner- 
vous system (including sweating, weakness, hunger, tremor, nausea, feelings of warmth, anxiety, and palpitations) [13-15, 50]. Because occasionally symptoms are not specific and insulinoma can mimic several pathological conditions, a broad differential diagnosis should be considered. A major distinction should be made between patients with insulinoma and non-insulinoma pancreatogenous hypoglycemia [86] and from hypoglycemia occurring after various gastric bypass surgeries for obesity. The latter is usually not fasting in nature, but is postprandial, and in some cases is caused by nesidioblastosis $[2,87$, 88]. However, the original description of Whipple's triad to suspect insulinoma remains fundamentally sound [15]. This triad consists of: (1) symptoms of hypoglycemia, (2) plasma glucose level $\leq 2.2 \mathrm{mmol} / \mathrm{l}$ ( $\leq 40 \mathrm{mg} / \mathrm{dl}$ ), and (3) relief of symptoms with administration of glucose.

Minimal Consensus Statements for Diagnosis of

Insulinomas - Specific [1-3, 13-15, 50, 66, 67, 89, 90]

Classically, clinical symptoms are required for the diagnosis of insulinoma and the diagnosis of insulinoma is absolutely established using the following six criteria: (1) documented blood glucose levels $\leq 2.2 \mathrm{mmol} / \mathrm{l}$ ( $\leq 40 \mathrm{mg} / \mathrm{dl}$ ); (2) concomitant insulin levels $\geq 6 \mu \mathrm{U} / \mathrm{ml}$ ( $\geq 36 \mathrm{pmol} / \mathrm{l}$; $\geq 3 \mathrm{U} / \mathrm{l}$ by ICMA); (3) C-peptide levels $\geq 200 \mathrm{pmol} / \mathrm{l}$; (4) proinsulin levels $\geq 5 \mathrm{pmol} / \mathrm{l}$; (5) $\beta$ hydroxybutyrate levels $\leq 2.7 \mathrm{mmol} / \mathrm{l}$, and (6) absence of sulfonylurea (metabolites) in the plasma and/or urine.

Further controlled testing includes the 72-hour fast, which is the classical gold standard for establishing the diagnosis of insulinoma, although some studies, but not others, report a 48 hour fast may be adequate $[1-3,13-15,50,66,67,89,90]$. When the patient develops symptoms and the blood glucose levels are $\leq 2.2 \mathrm{mmol} / \mathrm{l}$ ( $\leq 40 \mathrm{mg} / \mathrm{dl}$ ), blood is also drawn for C-peptide, proinsulin and insulin. Failure of appropriate insulin suppression in the presence of hypoglycemia substantiates an autonomously secreting insulinoma $[1-3,13-15,50,66,67,89,90]$.

Recently, increasingly, instead of using the standard insulin radioimmunoassay, which can cross-react in many cases with proinsulin, insulin-specific assays (immunoradiometiric, immunochemiluminescent assays) are being used which have no cross-reactivity with proinsulin and give lower insulin values (up to $60 \%$ of patients with insulinomas has insulin levels $\leq 6$ $\mu \mathrm{U} / \mathrm{ml}$ with these assays). In one recent comparative study the most sensitive criterion for diagnosing insulinomas using these assays was the combination of an elevated proinsulin level with a fasting glucose value $<45 \mathrm{mg} / \mathrm{dl}(<2.5 \mathrm{mmol} / \mathrm{l})$ [91].

\section{Minimal Consensus Statement on Diagnosis of RFTs -}

Specific

The minimal biochemical work-up for RFTs includes specific biochemical analyses related to the specific hormonal activity (example: serum glucagon in suspicion of glucagonoma), clinical symptoms of the disease and evidence of a hormone excess state. General markers such as serum chromogranin A may support the presence of a neuroendocrine tumor, be helpful for monitoring during the disease's course, but do not establish the diagnosis of a given RFT syndrome $[1,3,66,67]$. All biochemical tests should be performed at first visit. p-NETs causing Cushing's syndrome should be suspected from the clinical examination and history, and the diagnosis established by performing 24-hour urinary cortisol determinations, midnight plasma or salivary cortisol assessments and dexamethasone suppression tests as needed $[7,66]$.

Minimal Consensus Statement on Diagnosis of Other

Hormonal Syndromes in ZES Patients

Ectopic Cushing's syndrome develops in $5-15 \%$ of patients with advanced metastatic disease and has a very poor prognosis $[41,45]$. It should be routinely assessed for in patients with advanced metastatic disease by careful clinical examination, history and, if clinically suspected, routine 24-hour urinary cortisol determinations and serum cortisol assessment after dexamethasone suppression $[7,66]$. A secondary hormonal syndrome develops in $1-10 \%$ of patients, especially those with metastatic disease or MEN1 [64, 65]. These should be assessed for by a careful clinical history and routine hormonal assays are not recommended.

\section{Localization of Tumor/Tumor Extent in Patients with Functional p-NETs $[1,2,5,8,13-15,92-95]$}

\section{p-NET: Tumor Localization - General}

Tumor localization studies are required in all patients with p-NETs. All aspects of their management require knowledge of tumor extent. It is important to remember that the majority of all functional p-NETs (except insulinomas) (table 1) are malignant and that the natural history of p-NET is now the most important determinant of long-term survival in many studies, whereas in the past it was the control of the hormone excess state $[1,2,28,31$, 41]. Accurate localization of the tumor can result in complete surgical resection with cure of most insulinomas and a percentage of gastrinomas and other RFTs (10$40 \%)$. In gastrinoma patients, surgical resection whenever possible has been shown to decrease the subsequent rate of developing LM and increase survival [1, 2, 26, 50, 96-98].

Tumor localization studies are necessary to determine whether surgical resection is indicated, to localize the primary tumor, to determine the extent of the disease and whether metastatic disease to the liver or distant sites is present, and to assess changes in tumor extent with treatments.

Numerous localization studies have been recommended including conventional imaging studies (CT, MRI, ultrasound), selective angiography, functional localization methods (angiography with secretin or calcium stimulation and assessment of hepatic venous gastrin gradients, portal venous sampling for hormonal gradients), somatostatin receptor scintigraphy (SRS) and endoscopic ultrasound (EUS) as well as various intraoperative localization methods including intraoperative ultra- 
sound (IOUS), and in patients with gastrinomas, intraoperative transillumination of the duodenum and routine use of a duodenotomy $[2,5,8,9,15,18,92-95$, 99-101].

Most prospective studies show the sensitivity of conventional imaging studies for localizing the primary tumor is $10-50 \%$, angiography $20-50 \%$ and SRS $30-70 \%$ (except non-metastatic insulinomas) $[2,3,5,8,15,94]$. The use of SRS changes management in $15-45 \%$ of patients with gastrinomas and other RFTs $[2,8,9,18,100$ 102]. For SRS as well as all conventional studies, tumor size is an important variable and tumors $<1 \mathrm{~cm}$ are missed in $>50 \%$ of cases $[8,103]$. Therefore, because most duodenal gastrinomas are $<1 \mathrm{~cm}$, they are frequently missed. SRS has a much lower sensitivity in patients with localized insulinomas because they have lower densities of somatostatin receptors that bind the radiolabeled somatostatin analogue with high affinity (sst2, sst3, sst5) $[3,14,15,93]$. EUS is particularly sensitive for pancreatic NETs, however, its ability to detect small duodenal tumor is controversial $[8,15,47,104-106,119]$. Functional localization studies are not limited by tumor size but are invasive studies, and are now primarily reserved for insulinomas (intra-arterial calcium with hepatic venous insulin sampling) that are negative on other localization methods [8, 101, 107, 108]. Prospective studies show for metastatic disease from a malignant $\mathrm{p}$ NET to the liver that CT and ultrasound detect their presence in $30-80 \%$ of patients with metastases, MRI and angiography in $50-85 \%$ and SRS in $70-95 \%$ [1, 2, 8, $93,109,110]$. In patients that might have duodenal NETs such as those with ZES, at surgical exploration, duodenotomy is essential to detect up to one-half of duodenal tumors and its use increases the cure rate. IOUS should be routinely used to assess and identify pancreatic lesions $[5,8,15,99,111]$.

Recently, a number of studies have demonstrated that positron emission tomography (PET) especially with gallium-68-labelled somatostatin analogues when combined with CT has high specificity and is more sensitive that SRS or other modalities [1,94,112-118]. At present it is not available in many centers and the exact place in the localization algorithm it should be used has not been clearly defined. Standard PET with ${ }^{18} \mathrm{~F}$-glucose is not efficient in detecting well-differentiated tumors but may have some value in the detection of aggressive poorly differentiated pancreatic neuroendocrine carcinomas $(\mathrm{p}$ NECs) [5].

A striking wide discrepancy with regard to the results for localization between different centers for each of these techniques presumably reflects the specialist expertise and the availability of equipment. Still, no single modality is $100 \%$ effective. Any proposed imaging algorithm should take into account cost, sensitivity, availability and local expertise [15].

ZES: Minimal Consensus Statement on Gastrinoma

Localization $[1-3,8,9,18,47,92-96,100,106,110,119]$

Tumor localization studies are required in all patients with ZES biochemically established. Most recommend initially a UGI endoscopy with careful inspection of the duodenum followed by a mdCT or MRI and SRS $[8,18,94,96,100,110]$. If these studies are negative and surgery is being considered, EUS should be performed which will detect most pancreatic gastrinomas, but misses up to $50 \%$ of duodenal tumors $[47,106,119]$. If results are still negative $(<10 \%)$, selective angiography with secretin stimulation and hepatic venous gastrin sampling should be considered and should be performed in experienced centers [101]. SRS is the best study to initially stage the disease and detect both liver and distant metastases, however, SRS will miss $50 \%$ of tumors $<1 \mathrm{~cm}$ [103]. Recent studies show that MRI is a sensitive method for detecting LM of endocrine tumors [120]. IOUS and routine duodenotomy for duodenal lesions preferably preceded by transillumination of the duodenum should be done in all patients at surgery $[8,47,96]$. Bone metastases occur in up to one-third of patients with LM and should be sought in all patients by using SRS and an MRI of the spine [8, 121, 122]. PET scanning, especially combined with CT scanning (PET-CT), for gastrinomas as well as other p-NETs/duodenal NETs, is receiving increased attention because of its enhanced sensitivity/specificity. The results of ${ }^{18} \mathrm{~F}$-fluorodeoxyglucose $\left({ }^{18} \mathrm{~F}-\mathrm{FDG}\right) \mathrm{PET} / \mathrm{CT}$ imaging of gastrinomas are disappointing, presumably because of their low proliferative potential. Promising results reporting greater sensitivity than other modalities, however, have been obtained using ${ }^{11} \mathrm{C}-5$-HTP, ${ }^{18} \mathrm{~F}-\mathrm{DOPA}$, and ${ }^{68} \mathrm{Ga}$-DOTA-D-Phe ${ }^{1}$-Tyr ${ }^{3}$-octreotide $\left({ }^{68} \mathrm{Ga}\right.$-DOTATOC), however, all of these are investigational at present $[94,115,123]$.

MEN1: Minimal Consensus Statement on Neuroendocrine Tumor Localization - Specific [1, 2, 8, 11, 84, 85]

Patients with MEN1 not only develop p-NETs/duodenal NETs (functional and non-functional), but also tumors/hyperplasia of the parathyroid, pituitary, adrenal, skin, thyroid, CNS, smooth muscles as well as carcinoids (lung, thymus, gastric) [8, $11,12,53,55,79,84,85]$. In addition to initially screening for functional p-NETs/duodenal NETs, hyperparathyroidism and functional pituitary adenomas, as outlined in a previous section, all MEN1 patients need to be carefully assessed by physical examination and imaging studies for the other tumors, which are generally non-functional $[8,11,84,85]$. Specific parathyroid localization studies are required if hyperparathyroidism is found (ultrasound, CT/MRI, ${ }^{99 \mathrm{~m}} \mathrm{Tc}$-sestamibi scan) [84]. All patients require MRI of the sella turcica region and after 20 years of age require CT of the chest/abdomen [53, 55, 84]. If MEN1/ZES is present, UGI endoscopy for gastric carcinoids is recommended $[8,11,79]$. Routine SRS is not recommended if other imaging studies for NET are negative. EUS is more sensitive than crosssectional imaging studies (CT, MRI, US) for the detection of small non-functional pancreatic NETs, especially in the pancre- 
atic head/body region and to determine their size. Furthermore, the presence of multiple pancreatic tumors with EUS is very suspicious of MEN1. However, EUS is not generally recommended at present in all MEN1 patients, because routine surgical resection of small p-NETs $(<2 \mathrm{~cm})$ is not recommended and the EUS criteria on when to operate on these patients are not established $[8,11,124,125]$. Some experts recommended pancreatic EUS in selected MEN1 patients, especially if they have ZES or small non-functional p-NETs on other imaging studies and are being followed without surgery, in an attempt to detect small nonfunctional tumors and to follow their growth in order to offer earlier surgery $[8,124-126] .{ }^{68} \mathrm{Ga}-\mathrm{PET} / \mathrm{CT}$ is more sensitive than any of the other modalities, however its use remains investigational, and its role has not been defined in MEN1 patients [94].

Insulinoma: Minimal Consensus Statement on Tumor

Localization - Specific [13-15, 47, 92, 106, 108]

Insulinomas are almost universally within the pancreas $(1 / 3$ head $-1 / 3$ body $-1 / 3$ tail) and are characteristically small $p$ NETs $(82 \%<2 \mathrm{~cm}, 47 \%<1 \mathrm{~cm})$ and thus can be difficult to detect $[1,2,13-15,50]$. Ultrasound, CT, and MRI are widely available but positive in many studies in only $10-40 \%$ of cases. US or CT is usually the first study performed to rule out LM which occur in $<10 \%[13-15,26,95]$. SRS is positive in only $50 \%$ of localized insulinoma cases because of either a low density or lack of somatostatin receptors that bind octreotide with high affinity (sst2, sst5) $[1,2,13-15,93,110]$. Endoscopic US is positive in $70-95 \%$ of all cases if an experienced endoscopist is available and is thus is the imaging study of choice if the other non-invasive studies are negative $[13,15,47,106]$. Furthermore, EUS can help to determine if tumor enucleation is possible because it can evaluate the distance between the tumor and the pancreatic duct. Insulinomas like other $\mathrm{p}-\mathrm{NET}$ are vascular tumors, and selective angiography is positive in $60 \%$, however if combined with hepatic venous sampling for insulin after intra-arterial calcium administration, it is positive in $88-100 \%$ of cases $[13,50,107,108]$. This is an invasive study and requires specific expertise that may be only available in experienced centers. Recently, insulinomas have been shown to overexpress GLP-1 receptors and it has been shown that radiolabeled GLP-1 analogues can localize the insulinoma [127]. However, at present this study has only been performed in small number of cases and its possible general utility is unclear. IOUS is essential for localizing the insulinoma at surgery and determining the correct surgical procedure. PET with ${ }^{18} \mathrm{~F}-\mathrm{FDG}$ PET imaging of insulinomas is disappointing, presumably because of their low proliferative potential. Promising results, however, have been obtained using various PET/CT methods including ${ }^{11} \mathrm{C}-5$-HTP, and ${ }^{68} \mathrm{Ga}-\mathrm{DOTA}-\mathrm{D}-\mathrm{Phe}^{1}$-Tyr ${ }^{3}$-octreotide $\left({ }^{68} \mathrm{Ga}\right.$-DOTATOC) $[94,115,123,128]$. Although PET/CT remains investigational, in the small percentage of patients with insulinomas with negative imaging by the other methodologies (2-10\%), PET/CT with ${ }^{68} \mathrm{Ga}$-radiolabelebed somatostatin analogues $\quad\left({ }^{68} \mathrm{Ga}\right.$-DOTA-D-Phe ${ }^{1}-\mathrm{Tyr}^{3}$-octreotide $\quad\left({ }^{68} \mathrm{Ga}\right.$-DOTATOC)) should be considered in an experienced center.

Rare Functioning Tumors: Minimal Consensus Statement on Tumor Localization - Specific $[1-3,5,92,106]$

The combined use of mdCT scan (or MRI) and SRS-SPECT is always recommended $[2,5,92,95,120]$. Conventional imaging studies suggesting vascular or tissue invasion may provide im- portant information on whether surgical resection is contraindicated $[2,5,92,95,120,123]$. EUS is not universally recommended as a first-line procedure in the investigation of RFT of the pancreas; it may be used in circumstances where mdCT, MRI and SRS-SPECT are inconclusive, especially preoperatively; however, in patients with RFTs presenting with LM, EUS is rarely necessary. EUS may be helpful in patients with large or aggressive tumors to more clearly define the tumor involvement where surgery is considered. EUS-guided fine-needle aspiration is an effective and safe way to obtain tissue for pathological analysis of p-NETs $[5,106,126]$. Insufficient data is available to recommend PET/CT methods on a routine basis, its use remains investigational and availability is limited. If results with the aboverecommended imaging are unclear or negative in a patient with RFT, gallium-68-labeled somatostatin analogue PET should be considered with performance by an experienced center. Other examinations which may be useful are ${ }^{18} \mathrm{~F}$-DOPA-PET or ${ }^{11} \mathrm{C}-5$ HTP-PET (although availability and costs may have to be considered) $[1,2,94,115,123]$.

\section{Histopathology and Genetics of Functional p-NETs}

$$
[5,8,15,17,30,129-132]
$$

\section{Histopathology/Genetics - General}

The diagnosis of a specific functional p-NET type (table 1) requires the presence of a functional syndrome, combined with the appropriate diagnostic hormonal and functional studies and is supported by presence of a NET immunohistochemically expressing the appropriate hormone $[5,8,130,131]$. Immunohistochemistry is not essential for the diagnosis of a functional p-NET syndrome (table 1), but it provides verification of hormonal production, it may identify specific cell types, and it may provide information on the source of LM [130, 131]. Like other GI-NETs, p-NETs frequently produce multiple peptides, but they may or may not be released in sufficient quantities to cause serum elevations or a respective hormonal syndrome [2, 8, 129-131]. Hormone-producing NETs without a clinical syndrome are not considered a functional tumor syndrome. One exception is that most somatostatinomas in the literature are diagnosed only by immunohistochemistry and have no clinical or biochemical evidence of somatostatin ectopic release [2, $3,37]$, and thus because of the widespread occurrence of this practice, it has been suggested the term somatostatinoma syndrome be used for those with a functional tumor $[2,3]$.

In general, p-NETs do not show any histological features that specifically distinguish them from other foregut NETs. The histological features that are predictive of the biologic behavior of a given p-NET are discussed among the clinicopathological features and include an- 
gioinvasion, mitotic activity and the proliferative index determined by Ki67 staining.

In MEN1 with functional p-NETs the diagnosis of the functional p-NET is complicated by the multiple p-NETs that are invariably present microscopically and can become macroscopically $[5,8,16,17]$. Similarly in MEN1 patients with ZES due to a duodenal gastrinoma, they are almost invariably multiple $[8,11,16,17]$. In MEN1 patients with insulinomas the insulin-secreting tumors are intrapancreatic in location and frequently multiple [11, 15]. In most MEN1 patients with ZES ( $80-100 \%$ in various series) the gastrinoma(s) are in the duodenum and the pancreatic lesions seen on imaging studies are usually non-functional p-NETs $[11,16,17]$. In these patients, immunohistochemical studies with multiple hormones should be done on all primaries and metastases to help determine their origin $[17,131]$.

Pathological diagnosis can be obtained on tumor biopsy performed either in cases of hepatic metastases (e.g., ultrasound-guided biopsy) or of the primary tumor (preferably using EUS-FNA if locally advanced, or at surgery). Pathological diagnosis of RFTs is performed using conventional hematoxylin and eosin (HE) staining, and immunohistochemical staining with chromogranin A and synaptophysin $[5,8,131]$. Determination of mitotic index by counting $10 \mathrm{HPF}$ and/or calculation of Ki67 index by immunohistochemistry are mandatory as is assessment of the degree of invasion $[5,8,131]$. Recently, for p-NETs, WHO and ENETS TNM classification systems with grading have been proposed and numerous studies have validated their prognostic significance; therefore, it is important p-NETs be appropriate classified by these systems $[21,24,25,29,30,48,133-136]$.

Genetic testing for hereditary tumor syndromes should be performed in case of suspected familial predisposition to MEN1 or if the presence of other associated endocrinopathies (e.g., elevated serum calcium or PTH suggesting hyperparathyroidism and prolactin, respectively) after appropriate genetic counseling $[11,84,85]$.

\section{Minimal Consensus Statement on Pathology and Genetics of Gastrinomas - Specific $[1,2,8,11,84,85$, 130]}

\section{Pathology}

A detailed description of the macroscopic, microscopic and immunohistochemical findings are mandatory in order to support the diagnosis of gastrinoma and to allow for its correct classification using the current WHO TNM classification [20, 21, 30, 130-132, 137]. Histological examination on HE-stained sections must be accompanied by immunostaining for chromo- granin A, synaptophysin, and gastrin. Occasionally, immunohistochemistry using antibodies against bioactive products may be negative even in a case of the correct diagnosis $[17,138]$. Both a mitotic index using a mitotic count and a Ki67 index are mandatory. Immunohistochemistry for p53, SSR, and lymphovascular markers are optional. In MEN1 patients, all primaries and metastases should also be stained for the hormones responsible for the syndrome [131]. Cytology may be helpful, particularly in metastatic disease.

Genetics [11, 84, 85, 139]

Germline DNA testing for hereditary tumor syndromes in a patient with gastrinoma is only recommended in specific situations: a familial history or clinical/laboratory findings suggesting MEN1, VHL, tuberous sclerosis or the presence of multiple tumors. Mutational analysis should be performed to test for menin, VHL or tuberous sclerosis mutations (following informed consent). Genetic testing should be done according to approved methodology and prior to any genetic testing, genetic counseling should be performed.

\section{Minimal Consensus Statement on Pathology and Genetics of Insulinomas - Specific $[1,2,15,85,130]$}

Pathology

A detailed description of the macroscopic, microscopic and immunohistochemical findings is mandatory in order to support the diagnosis of insulinoma and to allow for its correct classification using the current WHO TNM classification [20, 21, 30, 130-132, 137]. Histological examination on HE-stained sections must be accompanied by immunostaining for chromogranin A, synaptophysin, and insulin. Both a mitotic index using a mitotic count and a Ki67 index are mandatory. The immunohistochemical determination of insulin expression by tumor cells is not absolutely necessary for diagnosis. Some insulinomas do not stain positively for insulin despite the correct diagnosis. This might be caused by the rapid release of insulin from the insulin-producing cells [15]. In patients with MEN1 with insulinomas, all primaries and metastases should be stained for insulin, whereas immunohistochemistry for PP, glucagon, and somatostatin to determine their full hormone expression, as well as for p53, SSR, and lymphovascular markers are optional. Cytology may be helpful, particularly in metastatic disease. In patients without MEN1 but with multiple insulinomas or multiple recurrences, insulinomatosis should be suspected [140].

Genetics [11, 84, 85, 139]

Germline DNA testing for hereditary tumor syndromes in a patient with insulinoma is only recommended in specific situations: a familial history or clinical findings suggesting MEN1, tuberous sclerosis or VHL, the presence of multiple tumors, or the demonstration of precursor lesions in the peritumoral pancreatic tissue. Mutational analysis should be performed to test for menin, VHL or tuberous sclerosis mutations (following informed consent). Genetic testing should be done according to approved methodology and prior to any genetic testing, genetic counseling should be performed. 


\section{Minimal Consensus Statement on Pathology and \\ Genetics of RTFs - Specific $[1,2,5,85,130]$}

Pathology

A detailed description of the macroscopic, microscopic and immunohistochemical findings is mandatory in order to support the diagnosis of RFT and to allow for its correct classification using the current WHO TNM classification [20, 21, 30, 130-132, 137]. Histological examination on HE-stained sections must be accompanied by immunostaining for chromogranin A, synaptophysin, and the specific hormonal syndrome suspected clinically. Both a mitotic index using a mitotic count and a Ki67 index are mandatory. Immunohistochemistry for p53, SSR, and lymphovascular markers are optional. In patients with MEN1 with RFTs, all primaries and metastases should be stained for insulin, in addition to PP, gastrin, glucagon and somatostatin to determine their full hormone expression. Cytology may be helpful, particularly in metastatic disease. In MEN1 patients, all primaries and metastases should also be stained for the hormones (gastrin, PP, glucagon, insulin, somatostatin) to determine the full spectrum of hormone expression. In the presence of multiple glucagon-containing tumors, glucagon cell adenomatosis should be considered [141].

Genetics [11, 84, 85, 139]

Germline DNA testing is only recommended in the presence of a positive family history of MEN1, if there are suspicious clinical findings or if multiple tumors or precursor lesions are present. Genetic analysis should also be performed in suspected cases of MEN1, VHL, neurofibromatosis-1, and tuberous sclerosis. Genetic testing, when performed, should include mutational screening and sequencing allowing the analysis of the entire coding gene and splice sites and genetic counseling should be sought prior to testing in all patients. Informed consent is mandatory prior to genetic testing. Genetic testing should be done according to approved methodology. Somatic (tumor) DNA testing is not recommended.

\section{Surgery with Functional p-NETs}

$[5,8,15,111,142-144]$

\section{Surgical Treatment of ZES[E1] - General}

$[2,8,9,47,96,145,146]$

There is now general agreement that patients with sporadic ZES with potentially resectable disease and without serious contraindications to surgery should undergo routine surgical exploration for cure [2, 8, 9, 47, 96, 145-147]. In both sporadic ZES and MEN1/ZES patients, 60-90\% of patients will be found to have duodenal gastrinomas, which are frequently small, are associated with positive lymph nodes in $40-60 \%$ of cases, are not seen on preoperative imaging studies or EUS, and can only be found at surgery if a duodenotomy is performed $[9,33,36,47,96$, 103 , 147]. Surgery should be performed by surgeons ex- perienced in treating these tumors. Surgical exploration with duodenotomy should be performed at a laparotomy and not laparoscopically $[8,47,96]$. The role of surgery, type, and timing of surgery in patients with MEN1/ZES remains controversial [11, 36, 47, 83, 146-149].

Total gastrectomy is no longer indicated unless in rare patients who cannot or will not take oral antisecretory drugs $(<1-2 \%)[8,47,96,150]$. Parietal cell vagotomy at the time of exploratory surgery is now rarely indicated, but patients who undergo surgery should receive antisecretory drugs in the preoperative period to avoid complications related to acid residual secretion $[8,47]$. In highly selected patients, pancreaticoduodenotomy may be indicated and Whipple resections can result in cure in patients with pancreatic head/duodenal gastrinomas in both sporadic and MEN1/ZES patients $[8,47,111,142$, $147,148]$. However, its use is not generally recommended. It may have a role in the few selected patients with long life expectancy with multiple or large gastrinomas in this region that are not removable by enucleation $[8,47,142$, 147]. After curative resection it is essential to regularly evaluate patients for continuing cure by performing both FSG assessments as well as secretin testing $[8,18,151]$. Repeated conventional imaging studies are not needed if the fasting gastrin and secretin test remain normal $[8,18$, 151]. Whether SRS will detect recurrent tumor before fasting gastrin elevations or a return of a positive secretin test is unknown at present $[8,47,103,151]$.

\section{Minimal Consensus Statement on Surgical Treatment for Gastrinoma - Specific [3, 8, 9, 11, 47, 96, 111, 142, $145,146,148,150]$}

Due to efficacy of PPIs, total or partial gastrectomy is no longer indicated $[8,47,75,96,150]$. For sporadic gastrinoma, surgery including complete resection of the primary and involved lymph nodes is the only curative treatment $[8,47,96,145,147]$. Surgery has been shown to decrease the rate of development of LM which is the most important prognostic factor for long-term survival and to increase disease-related survival [97, 98, 152]. Therefore, surgery for cure is recommended in patients with sporadic ZES without LM or comorbidity limiting life expectancy. Long-term cure after surgery (excluding pancreaticoduodenectomy) occurs in $20-45 \%$ of patients with sporadic ZES, but in $0-1 \%$ of patients with MEN1/ZES [18, 47, 147, 149]. Pancreatic tumors distant from the pancreatic duct can be enucleated. Resections are required when tumor is close to pancreatic duct $(<3 \mathrm{~mm})$. Distal pancreatic resection should be performed for caudally located tumors and duodenotomy performed routinely to detect small duodenal gastrinomas $[8,47,96,99,142,145,153]$. For sporadic left-sided pancreatic gastrinoma, central or distal pancreatectomy (with or without splenectomy) can be proposed [8, 47, 96, 99, $142,145,153]$. In highly selected patients with pancreatic head 
gastrinoma and those with local recurrence or persisting tumor after previous surgery, pancreaticoduodenectomy may be an alternative $[8,47,142,148,154]$. For sporadic gastrinomas, independent of the primary location, both routine regional lymphadenectomy and intraoperative liver exploration should be performed, because lymph node and LM from duodenal/pancreatic gastrinomas are frequent and lymph node and hepatic primary tumors are reported, although controversial $[8,47,96,155]$. Up to $30 \%$ of sporadic gastrinomas are not located precisely by preoperative explorations. In this setting, surgical exploration may be controversial and a multidisciplinary discussion should review the case and decide whether or not to perform surgery. When decided, surgery should include complete abdominal cavity exploration through laparotomy, intraoperative pancreatic ultrasound, duodenotomy (with duodenal transillumination) and routine lymphadenectomy (at least in the gastrinoma triangle) $[2,3,8,96,145,155,156]$.

In MEN1/ZES, surgery without a Whipple resection is associated with $>90 \%$ of recurrence $[8,11,47,52,147,149,157]$. Therefore, routine surgical exploration is controversial in patients with MEN1/ZES [8, 11, 47, 52, 146-148, 157]. Indeed, these patients usually have multiple duodenal gastrinomas, frequently with lymph node metastases, with other p-NETs (non-functional primarily), are rarely cured and have an excellent life expectancy if only small tumors $(<2 \mathrm{~cm})$ or no tumors are present on preoperative imaging studies $[8,11,36,52,96,125]$. However, surgery is the only approach that might lead to prevent (or cure) malignant transformation [157]. Since MEN1 patients with pancreatic tumors $<2 \mathrm{~cm}$ have spontaneous good long-term life expectancy, it has been generally recommended that surgery for prevention of metastatic dissemination could be restricted to MEN1 pancreatic tumors $>2 \mathrm{~cm}[8,11,47,52,125]$. Even if some limited series reported potential long-term biochemical remission after pancreaticoduodenotomy in MEN1-ZES patients, the real impact on the long-term survival remains controversial and the long-term side effects of pancreaticoduodenotomy remain largely undefined $[8,9,96,142,146,148,157]$.

In contrast to the case for insulinomas, laparoscopic resection of gastrinomas is controversial and not generally recommended, because frequently the primary is not seen on preoperative imaging studies, the tumors are submucosal in the duodenum and they frequently have lymph node metastases $[8,47,96,158]$.

\section{Surgical Treatment of Insulinomas - General}

$[2,13-15,26,50,159]$

In contrast to gastrinomas and some RFTs (somatostatinomas, GRHomas) (table 1), insulinomas are often unique in that they are in benign in $90 \%$ and located, similar to a few other RFTs (table 1) (i.e. glucagonomas, $>90 \%$ VIPomas) entirely within the pancreas $[2,13$ 15]. This intrapancreatic location facilitates the localization with EUS, which has a greater sensitivity/specificity for intrapancreatic than extrapancreatic localization of p-NETs. However, when insulinomas are small $(<1 \mathrm{~cm})$, which is not infrequent, preoperative localization and detection at surgery can be difficult. Furthermore, insulinomas have a lower detection rate with SRS because of lower densities of somatostatin receptors and therefore are frequently $(>50 \%)$ missed during SRS studies preoperatively $[2,13-15,26,47,50]$. Insulinomas also differ from the other PETs in that they are malignant in $<10 \%$ of cases (table 1) and therefore have a very high probability of cure $(>90 \%)[2,13-15,26,50,159]$. In contrast to the other PETs, laparoscopic resection is increasingly used in patients with insulinomas in whom the tumor can be localized preoperatively [26, 158-161].

\section{Minimal Consensus Statement on Surgical Treatment of Insulinoma - Specific$$
[3,8,9,11,47,96,111,142,145,146,148,150]
$$

For sporadic insulinoma, the standard surgical treatment should include pancreas exploration by both palpation and IOUS. When the tumor is located further than $2-3 \mathrm{~mm}$ from the pancreatic duct, an enucleation is preferred to pancreatic resection. Otherwise, a partial pancreatic resection (central or distal or pancreatic head resection) is needed. In all settings, no lymphadenectomy is needed $[3,8,9,11,47,96,111,142,145,146,148$, 150]. If the insulinoma is localized preoperatively, enucleation from the pancreatic body/tail and distal pancreatectomy can be performed safely by laparoscopy $[8,26,158,159,161,162]$. When a sporadic insulinoma is not localized preoperatively, surgical exploration is indicated $[3,8,9,11,47,96,111,142,145,146,148$, 150]. Intraoperative tumor location can require, additionally to IOUS, intraoperative insulin sampling and frozen section [163]. In rare patients with suspicion of malignant insulinoma or recurrence, a radical surgery aiming to treat either locoregional recurrence and/or LM is indicated. When insulinoma is not located either preoperatively or intraoperatively including samplings, blind distal resection is not recommended $[3,8,9,11,47$, $96,111,142,145,146,148,150]$.

In the presence of MEN1, in which multiple tumors are frequently present, the aim of surgery is to control inappropriate insulin secretion by excising all insulinomas. Preoperative localization of which pancreatic tumors are the insulinomas is mandatory, because these patients frequently have other pancreatic NETs (which are usually non-functional) $[2,11,52,142]$. In these patients, preoperative intra-arterial calcium injections with hepatic venous insulin sampling as well as intraoperative insulin sampling may be required $[8,11,50,107,163]$.

\section{Surgical Treatment of RFTs - General}

$[2,5,111,142,144]$

Indications for surgery depend on clinical symptom control, tumor size/location/extent, malignancy and metastatic spread $[1,2,5,111,142,144]$. Curative surgery should be sought whenever possible, even in the presence of metastatic disease, including 'localized' metastatic disease to the liver, if thought potentially resectable and the patient can tolerate the surgery $[1,2,5,111,142,144]$. The type of surgery depends on the location of the primary 
tumor - pancreaticoduodenal resection (Whipple's operation), distal pancreatic resection, tumor enucleation or enucleation in combination with resection. Since malignancy is frequent in RFTs, adequate lymph node clearance is mandatory $[1,2,5,111,142,144]$. In the case of localized LM or more extensive disease spread, surgery should also be considered if at least $90 \%$ of gross tumor is thought resectable $[8,98,142,152,164-169]$, as discussed in a latter section.

\section{Minimal Consensus Statement on Surgical Treatment of RFTs - Specific $[2,5,98,111,142,144,167]$}

Curative surgery is always recommended whenever feasible after optimal symptomatic control of the clinical syndrome by medical treatment. Due to the usually large size of the tumor and the high prevalence of LM in RFT, curative surgery should include pancreatic resection with lymphadenectomy through laparotomy. Laparoscopic resection is not recommended because of the need for lymphadenectomy and careful inspection for invasion/metastases [5]. Bilateral adrenalectomy can be indicated in some selected patients with Cushing syndrome $[2,5,111]$. Surgery of LM may be performed during treatment of the primary tumor. Cytoreductive surgery should be considered when the metastatic disease is localized or if $>90 \%$ of tumor load is thought resectable which may help to improve hormonal control and perhaps extend survival, although this is not proven $[8,142$, 152, 164-169]. This will be discussed in the next section.

\section{Minimal Consensus Statement on Surgical Treatment} of Advanced Symptomatic p-NETs - Specific

$[2,5,8,15,98,111,142,144,164,165,167-169]$

Symptomatic control of the hormone excess state of all functional p-NETs may be facilitated by therapy directed against the tumor per se in the form of cytoreductive surgery either alone or combined with RFA. Cytoreductive surgery should be considered when the metastatic disease is localized or if $>90 \%$ of tumor load is thought resectable $[8,98,142,152,164-169]$. RFA can also be used with resection or alone through laparoscopic approach if there are $<10$ lesions seen in the liver and if the largest tumor is $<5 \mathrm{~cm}$ (ideally $<3 \mathrm{~cm}$ ) in diameter $[5,152,170]$. Laparoscopic RFA has resulted in control of symptoms in $>90 \%$ of patients with malignant p-NETs [170].

\section{Medical Treatment of Functional p-NETs}

\section{$[1,2,5,8,13-15,57,168,169,171]$}

Medical Treatment of ZES: Treatment of the Gastric Acid Hypersecretion - General [2, 3, 8, 32, 57, 172, 173]

It is essential to control the gastric acid hypersecretion in all patients to prevent peptic complications which can rapidly develop in these patients, because the basal gastric acid output can be $>5$ normal in many patients with ZES (mean $45 \mathrm{mEq} / \mathrm{h}$ ) $[8,61]$. Both $\mathrm{H}_{2}$ blockers and PPIs can control acid hypersecretion in all patients who can take oral medications and are cooperative $[2,8,32,57,172$, 173]. The preferred drugs are now PPIs, because of their long duration of action $[8,32,57,172,174-178] . \mathrm{H}_{2}$ blockers to be effective are usually required at higher doses than used in conventional peptic disease (frequently up to 10 times the usual dose) and $4-6 \mathrm{~h}$ dosing is frequent $[2,3,57,75]$. Patients have been treated for up to 15 years with PPIs with no evidence of tachyphylaxis and no doserelated side effects. Vitamin $B_{12}$ deficiency but not iron deficiency has been reported with long-term PPI use in ZES, but it is unclear if it causes clinically significant vitamin $B_{12}$ deficiency $[8,179-181]$. Although either intravenous PPIs (intermittent use) or continuous infusion of high doses of $\mathrm{H}_{2}$ blockers can satisfactorily control acid secretion when parenteral drug is needed $[2,3,8,32,57$, 75], because of the intermittent use parenteral PPIs are recommended. In patients with MEN1/ZES the correction of the hyperparathyroidism can reduce the fasting gastrin level, $\mathrm{BAO}$, and increase the sensitivity to acid antisecretory drugs $[82,83]$. Gastric acid hypersecretion can continue even after a curative resection in up to $40 \%$ of the patients and require low doses of antisecretory drugs $[182,183]$. Although rarely used at present, a parietal cell vagotomy can reduce the $\mathrm{BAO}$ long term and decrease the dosage of antisecretory drug needed [8].

\section{Minimal Consensus Statement on Medical Treatment of the Gastric Acid Hypersecretion in ZES Patients - Specific}

Acid hypersecretion needs to be controlled acutely and longterm in all ZES patients to prevent acid-related peptic complications $[8,57,75,172,173,175,176]$. PPIs are the drugs of choice because of their long duration of action allowing once or twice a day dosing in most patients. Studies show all available PPIs (omeprazole, lansoprazole, pantoprazole, rabeprezole, esomeprazole) are effective $[8,32,57,172,174-178]$. The recommended starting dose is equivalent to omeprazole $60 \mathrm{mg}$ once per day in sporadic ZES and 40-60 mg b.i.d. in MEN1/ZES [8, 57, 75, $172,173,175,176]$. To control acid hypersecretion in ZES patients with complicated disease (presence of MEN1 with hypercalcemia, presence of severe GERD symptoms, presence of previous Billroth II resection), higher doses of all antisecretory drugs are required and more frequent dosing may be needed, even with PPIs $[8,75,82,83,184]$. In these patients, PPIs should be started at equivalent to $40-60 \mathrm{mg}$ b.i.d of omeprazole. On follow-up visits, PPI drug dosage can be reduced in most patients with sporadic ZES and in 30-50\% of MEN1/ZES patients. With long-term treatment, serum vitamin $\mathrm{B}_{12}$ levels should be 
monitored once per year [8, 179-181]. Recent studies suggest an increased incidence of bone fractures, particularly of the hip in patients on continuous long-term PPIs, although no studies have been performed specifically on ZES patients $[179,180]$. The exact mechanism that PPIs may be producing bone fractures is unclear and no specific recommendations have been generally accepted for the follow up of patients maintained long term on PPIs. Oral doses of histamine $\mathrm{H}_{2}$ receptor antagonists can also be effective, but high, frequent dosing is required [8, 57, 75]. During periods when oral drugs cannot be taken such as during surgery, parenteral PPIs are the drugs of choice, although a continuous infusion of histamine $\mathrm{H}_{2}$ receptor antagonist can also be effective but high doses are required $[8,57,75]$. Long-acting somatostatin analogues also control acid secretion, but they are not recommended for this purpose in ZES, because of the ease and effectiveness of PPIs, which can be given orally.

\section{Medical Treatment of Insulinoma: General}

$[13-15,185]$

Appropriate dietary management can help prevent prolonged periods of fasting. Because the vast majority of patients with insulinomas can be cured surgically, medical management is reserved only for preoperative control of blood glucose levels, for patients with unresectable metastatic disease, or for patients who are unable or unwilling to undergo surgical treatment [13-15, 26, 50].

\section{Minimal Consensus Statement on Medical Treatment of Insulinoma - Specific}

Prior to surgery or in patients with metastatic insulinomas, in addition to frequent small feedings and intravenous glucose administration, the hypoglycemia frequently needs to be controlled by drug therapy. Diazoxide $(50-300 \mathrm{mg} / \mathrm{day}$, can be increased up to $600 \mathrm{mg} /$ day) inhibits insulin release by direct action on the $\beta$ cells [2,13-15]. Diazoxide is the most effective drug for controlling hypoglycemia [2, 13-15]. However, side effects are: edema, weight gain, renal impairment, and hirsutism. Verapamil and diphenylhydantoin have also been reported to be successful in the control of hypoglycemia. In refractory cases, glucocorticoids such as prednisolone can be effective as well. Somatostatin analogues like octreotide and lanreotide can be useful in preventing hypoglycemia in those patients with somatostatin receptor subtype 2-positive tumors, but can worsen hypoglycemia in some patients [185]. Interferon- $\alpha$ has been shown to be beneficial in selected cases. Recently, in a small number of cases with malignant insulinomas, mTOR inhibitors (everolimus, rapamycin) have controlled the insulin secretion and hypoglycemia $[2,3,186-188]$.

\section{Medical Treatment of RFT Functional Syndrome-}

General [2, 3, 5, 171]

In the past, patients frequently died from the untreated effects of the hormone excess state, therefore it is important it be controlled $[2,5,42]$. This can be accom- plished in most cases at present by using a combination of medical, surgical, radiological approaches. Only the medical aspects are dealt with in detail here because treatment directed at the tumor per se which can also help control the functional aspects of the p-NET in patients with advanced disease is dealt with in a separate chapter. Both somatostatin analogues and interferon have been shown to be effective in the control of symptoms in functioning p-NETs and this also includes RFTs $[1-3,5,171]$. Approximately $80-90 \%$ of patients with VIPomas and glucagonoma improve very promptly, overcoming diarrhea and skin rash, and $60-80 \%$ have a reduction in VIP and glucagon levels [1-3, 5, 171]. Symptomatic relief is not always related to reduction in circulating hormone levels, indicating that somatostatin analogues have direct effects on the peripheral target organ. Escape from symptomatic control can be seen quite frequently but an increase in the dose of somatostatin analogues can help temporarily [1-3, 5, 171]. Somatostatin analogues can also have anti-growth effects on p-NETs, and that is covered in the chapter on the treatment of advanced disease. For the control of symptoms, somatostatin analogue therapy should be initiated with short-acting substance (octreotide $100 \mu$ g s.c. $\times 2-3$ ) for $1-2$ days with titration according to clinical response. Then the patient can be transferred to slow-release Lanreotide-SR ${ }^{\circledR}$ i.m. Lanreotide autogel ${ }^{\circledR}$ s.c. or Sandostatin-LAR ${ }^{\circledR}$ i.m. (every 4 weeks) $[5,189]$. Likewise, interferon- $\alpha$ treatment may help control symptoms of the hormone excess state in functional low proliferating tumors although it has been less well studied than the use of somatostatin analogues. It is reported to be effective in VIPomas not responding to somatostatin analogues and also in isolated cases when combined with somatostatin to control the symptoms of a functional p-NET, which with somatostatin treatment alone there was inadequate symptom control, however, this requires confirmation in a controlled manner $[1,5,190]$.

\section{Minimal Consensus Statements on Medical Treatment of RFT Functional Syndrome - Specific [2, 3, 5, 171]}

Somatostatin analogues are an effective treatment in the control of symptoms in RFTs, especially in patients with VIPomas, GRHomas and glucagonomas [2, 3, 5, 50, 171]. Long-acting somatostatin analogues are also reported to be effective in controlling the ectopic hormone secretion in some cases of somatostatinomas. In patients with Cushing's syndrome, the majority of which have metastatic disease at presentation, primarily adrenal-blocking agents (ketoconazole, metyrapone) are used prior to adrenectomy. In some cases long-acting somatostatin ana- 
logues may be effective and there is increased interest in the use of glucocorticoid receptor antagonists, like mifepristone, which are investigational at present [191, 192]. If somatostatin analogues are ineffective or lose efficacy in controlling the hormone excess state, treatment with interferon- $\alpha$ may be effective at controlling the symptoms either alone or in combination with somatostatin analogues. Promising results with the multiligand somatostatin receptor congener pasireotide have recently been presented. Also, the dopamine agonist cabergoline might have a role in controlling ectopic ACTH secretion [191, 193, 194].

\section{Medical Treatment of Functional p-NET Syndromes}

in Patients with Advanced, Metastatic Disease -

General

Treatment of advanced disease is updated in a separate and comprehensive chapter [195]. Here, is a brief summary.

Somatostatin analogues may be of value also in subgroups of patients with slowly progressive low proliferative NET (G1) of pancreatic and gastroduodenal origin and its use is supported by literature data on retrospective and non-randomized prospective trials in more than 500 patients [171, 196-198]. In patients with gastric carcinoids, somatostatin analogues have been shown to exert anti-proliferative effects in animals and in man, however, data is not available in cases of LM [199].

Two prospective randomized trials in metastatic gastroenteropancreatic NET have shown that somatostatin analogues, IFN or the combination of both have comparable anti-proliferative effects when used after prior disease progression [196, 197].

Chemotherapy is recommended in pancreatic NET, G2 foregut NET of extrapancreatic site, and in neuroendocrine carcinoma (G3) of any site. Systemic cytotoxics are indicated in patients with inoperable progressive LM from well-differentiated NET of pancreatic tumor origin using combinations of streptozotocin and 5-FU and/or doxorubicin with objective response rates in the order of 35-40\% [199-201]. These response rates are considerably lower than the $69 \%$ reported by Moertel et al. [202] in 1992. There is long-standing experience with streptozotocin-based chemotherapy since the 1980s. Other newer chemotherapy regimens report higher response rates with various regimens and thus show promise, but larger confirmatory studies are needed (5-fluorouracil, dacarbazine, epirubicin [203] or capecitabine and temozolomide) [204]. Also transarterial embolization and/or chemoembolization as well as liver-directed therapy with radiolabeled particles, each of which have been shown to have tumor response rates of $\geq 50 \%$, should be considered in patients with liver predominate metastases, especially with functional pNETs difficult to control [205-207].
PRRT is considered in both functioning and non-functioning NET and irrespective of the primary tumor site. Based upon small phase II trials and retrospective data, partial remission rates range between 0 and 33\% [208, 209] and are higher in pancreatic compared to midgut NET. In a prospective multicenter phase II trial with ${ }^{90} \mathrm{Y}-$ edotreotide in patients with refractory carcinoid syndrome, partial remission rate was $4 \%$ and disease stabilization rate $70 \%$. PFS was favorable with 16.3 months [210].

Regarding new molecular targeted therapies, both drugs, everolimus and sunitinib, are novel treatment options in advanced p-NET. Everolimus is thus a treatment option after failure of chemotherapy in p-NET, but can be considered as first-line therapy in selected cases as an alternative treatment to locoregional therapies or chemotherapy.

The RADIANT-3 study (everolimus) included 40\% therapy-naive patients, and efficacy was equally good in therapy-naive patients as in patients with previous therapies [211]. An early unselected use of the drug cannot be recommended, because long-term toxicity data are lacking, however, it is licensed in many countries for use in progessive p-NETs.

Results from a phase III placebo-controlled trial support the efficacy of sunitinib, a multiple tyrosine kinase inhibitor that targets PDGF-R, VEGF-R, c-kit, RET and FLT-3, in progressive p-NET [223, 224].

The majority of the patients had undergone prior systemic therapy, especially systemic chemotherapy. The main indication of sunitinib is its use as a second- or third-line therapy. Sunitinib should be considered as first-line therapy only in selected cases as an alternative treatment option if somatostatin analogues, chemotherapy and/or locoregional therapies are not feasible or promising. The role of everolimus and sunitinib in advanced disease is discussed in detail in the chapter on treatment of advanced progressive p-NETs.

\section{Minimal Consensus Statements on Medical Treatment of Functional p-NET Syndromes in Patients with Advanced, Metastatic Disease - Specific $[5,8,15,212,213]$}

The control of the hormone excess state in patients with advanced disease is similar to that outlined above for the typical patient with a p-NET, except that some added features need to be considered. Not infrequently a patient with advanced disease (non-gastrinoma) becomes refractory to the effect of medical therapy (somatostatin analogues and/or interferon, etc.) and the hormone excess state cannot be satisfactorily controlled. This does not occur with gastrinomas because PPIs are effective even 
with extensive disease. If symptomatic refractory disease develops this can be an indication to consider various anti-tumor therapies including liver directed therapies (embolization, chemoembolization, RFA, radiolabeled microspheres), PRRT or cytoreductive surgery, all of which are reported to improve symptomatic control in many patients $[8,15,111,142,152,164,166-$ 169, 212-218]. With these different modalities, symptoms improve in $40-80 \%$ of patients [167-169, 208, 218, 219].

The early combination use of somatostatin analogues and IFN for anti-proliferative purposes is not recommended. Also, the use of PRRT cannot be recommended as first-line therapy, but after failure of medical therapy. The presence of a strong expression of sstr 2 as visualized by somatostatin receptor imaging is a prerequisite for the use of PPRT. The minimum requirements for PRRT are reported in a separate consensus guideline [220]. Everolimus and sunitinib represent novel therapeutic options in patients with surgically non-resectable progressive pancreatic NET as alternative or after progression following chemotherapy $[211,223,224]$.

\section{Follow-Up of Patients with Functional p-NETs}

(table 1) [2, 3, 5, 8, 221]

\section{Follow-Up of Patients with Functional}

p-NETs - General

Patients with functional p-NETs with MEN1, with advanced metastatic disease, post-curative resection, or with active disease problems frequently require a different follow-up schedule than the typical p-NET patient with active but limited disease. Patients with MEN1 after initial treatment of the MEN1 problems (hyperparathyroidism, pituitary disease) should be seen at 6- to 12 -month intervals and other MEN1 problems also investigated. Patients post-curative resection can be evaluated yearly unless symptoms of recurrence occur. $\mathrm{Pa}$ tients with metastatic disease require a relatively short follow-up initially (3-6 months) to determine whether progressive disease is present and interfering with symptomatic control and whether anti-tumor treatment might be needed to facilitate symptom control.

\section{Minimal Consensus Statement on Follow-Up of Patients with Gastrinoma - Specific$$
[2,3,8,18,75,221]
$$

All patients with active non-metastatic disease should be seen initially at 3-6 months and then if stable yearly. At each evaluation, biochemical studies (vitamin $\mathrm{B}_{12}$ level, ionized calcium, $\mathrm{PTH}$, gastrin), assessment of acid control if possible and tumor imaging studies (abdominal CT or MRI yearly, SRS at least every 3 years) should be done. For patients with MEN1/ZES, follow-up should be yearly with an assessment of tumor extent with imaging (CT/MRI abdomen and chest CT (rule out thymic carcinoid, especially in men every $3-5$ years), SRS at least every 3 years, pituitary MRI every 3-5 years), biochemical assessment for MEN1 diseases (ionized calcium, serum PTH, prolactin, insulin), FSG, acid control if possible, UGI endoscopy to evaluate for gastric carcinoid $[8,11,55,79,83,84]$. For patients with postcurative resection, yearly evaluation with fasting gastrin levels, secretin provocative test and acid secretory control should be done if the patient is still taking PPIs/ $\mathrm{H}_{2}$ blockers $[8,18,151]$. Imaging modalities should be performed if ZES is not cured, according to previous indications.

For patients with advanced metastatic disease, follow-up should be at 3- to 6-monthly intervals with tumor imaging (CT or MRI and SRS (when clinically indicated)), FSG and acid secretory control (6 months). At least yearly, assessment for ectopic Cushing's with a urinary cortisol and serum cortisol should be considered. For patients with advanced metastatic disease or who are receiving chemotherapy or other antitumor treatments, follow-up may need to be shorter to assess for specific toxicities. Treatment of advanced disease is dealt with separately in a later chapter.

\section{Minimal Consensus Statement on Follow-Up in \\ Patients with Insulinoma - Specific [2, 3, 13, 15, 221]}

Follow-up for insulinoma patients without MEN1 post-resection should be at 3-6 months and then if continued cured only if symptoms recur [213]. Post-curative resection patients with multiple insulinomas or with MEN1 should be followed yearly and also re-evaluated at any time symptoms recur. At follow-up in addition to a careful history for fasting hypoglycemic symptoms, a fasting glucose, insulin, C-peptide and proinsulin measurement should be done.

\section{Minimal Consensus Statement on Follow-Up for \\ Patients with RFTs - Specific [2, 3, 5, 213]}

Follow-up for patients with RFTs should be at 3- to 6-month intervals with metastatic disease and yearly in patients without metastatic disease. Following treatment, in patients with no evidence of residual disease, pertinent biochemical assessment (i.e. hormones known to be elevated prior to treatment, both specific and non-specific) should be initially performed and, when negative, further tests are not usually required. For patients with residual disease, specific markers coupled with contrast-enhanced mdCT scan or MRI and SRS (when clinically indicated) should be performed.

\section{Complete List of Participants}

List of Participants of the Consensus Conference on the 2011 Consensus Guidelines for the Management of Patients with

Digestive Neuroendocrine Tumors: An Update

Martin Anlauf, Germany (Martin.Anlauf@gmx.de)

Rudolf Arnold, Germany (arnoldr@staff.uni-marburg.de)

Detlef Bartsch, Germany (bartsch@med.uni-marburg.de) 
Eric Baudin, France (baudin@igr.fr)

Richard Baum, Germany (info@rpbaum.de)

Maria Luisa Brandi, Italy (m.brandi@dmi.unifi.it)

Guillaume Cadiot, France (gcadiot@chu-reims.fr)

Frederico Costa, Brazil (frederico.costa@hsl.org.br)

Martyn Caplin, UK (m.caplin@medsch.ucl.ac.uk)

Anne Couvelard, France (anne.couvelard@bjn.aphp.fr)

Wouter de Herder, The Netherlands

(w.w.deherder@erasmusmc.nl)

Gianfranco Delle Fave, Italy (gianfranco.dellefave@uniroma1.it)

Timm Denecke, Germany (timm.denecke@charite.de)

Barbro Eriksson, Sweden (barbro.eriksson@medsci.uu.se)

Massimo Falconi, Italy (massimo.falconi@univr.it)

Thomas Gress, Germany (gress@med.uni-marburg.de)

David Gross, Israel (gross@vms.huji.ac.il)

Ashley Grossman, UK (a.b.grossman@qmul.ac.uk)

Robert Jensen, USA (robertj@bdg10.niddk.nih.gov)

Gregory Kaltsas, Greece (gkaltsas@endo.gr)

Fahrettin Kelestimur, Turkey (fktimur@erciyes.edu.tr)

Reza Kianmanesh, France (reza.kianmanesh@lmr.ap-hop-paris.fr)

Günter Klöppel, Germany (guenter.kloeppel@alumni.uni-kiel.de)

Klaus-Jochen Klose, Germany (klose@med.uni-marburg.de)

Ulrich Knigge, Denmark (knigge@mfi.ku.dk)

Paul Komminoth, Switzerland (paul.komminoth@triemli.stzh.ch)

Beata Kos-Kudla, Poland (beatakos@ka.onet.pl)

Eric Krenning, The Netherlands (e.p.krenning@erasmusmc.nl)

Dik Kwekkeboom, The Netherlands

(d.j.kwekkeboom@erasmusmc.nl)

Jose Manuel Lopes, Portugal (jmlopes@ipatimup.pt)
Bruno Niederle, Austria (bruno.niederle@meduniwien.ac.at)

Ola Nilsson, Sweden (ola.nilsson@llcr.med.gu.se)

Kjell Öberg, Sweden (kjell.oberg@medsci.uu.se)

Juan O’Connor, Argentina (juanoconnor@hotmail.com)

Dermot O'Toole, Ireland (dermot.otoole@tcd.ie)

Ulrich-Frank Pape, Germany (ulrich-frank.pape@charite.de)

Mauro Papotti, Italy (mauro.papotti@unito.it)

Andreas Pascher, Germany (andreas.pascher@charite.de)

Marianne Pavel, Germany (marianne.pavel@charite.de)

Aurel Perren, Switzerland (aurel.perren@pathology.unibe.ch)

Ursula Plöckinger, Germany (ursula.ploeckinger@charite.de)

Guido Rindi, Italy (guido.rindi@rm.unicatt.it)

Philippe Ruszniewski, France

(philippe.ruszniewski@bjn.aphp.fr)

Ramon Salazar, Spain (ramonsalazar@iconcologia.net)

Hironobu Sasano, Japan (hsasano@patholo2.med.tohoku.ac.jp)

Alain Sauvanet, France (alain.sauvanet@bjn.aphp.fr)

Jean-Yves Scoazec, France (jean-yves.scoazec@chu-lyon.fr)

Thomas Steinmüller, Germany

(t.steinmueller@drk-kliniken-westend.de)

Anders Sundin, Sweden (anders.sundin@radiol.uu.se)

Babs Taal, The Netherlands (b.taal@nki.nl)

Paola Tomassetti, Italy (paola.tomassetti@unibo.it)

Eric Van Cutsem, Belgium (eric.vancutsem@uzleuven.be)

Marie-Pierre Vullierme, France

(marie-pierre.vullierme@bjn.aphp.fr);

Bertram Wiedenmann, Germany

(bertram.wiedenmann@charite.de).

\section{References}

1 Oberg K: Pancreatic endocrine tumors. Semin Oncol 2010;37:594-618.

$\checkmark 2$ Metz DC, Jensen RT: Gastrointestinal neuroendocrine tumors: Pancreatic endocrine tumors. Gastroenterology 2008;135:14691492.

-3 Kulke MH, Anthony LB, Bushnell DL, et al: NANETS Treatment Guidelines: well-differentiated neuroendocrine tumors of the stomach and pancreas. Pancreas 2010;39: 735-752.

4 Ekeblad S: Islet cell tumours. Adv Exp Med Biol 2010;654:771-789.

5 O’Toole D, Salazar R, Falconi M, et al: Rare functioning pancreatic endocrine tumors. Neuroendocrinology 2006;84:189-195.

-6 Falconi M, Plockinger U, Kwekkeboom DJ, et al: Well-differentiated pancreatic nonfunctioning tumors/carcinoma. Neuroendocrinology 2006;84:196-211.

7 Kaltsas G, Androulakis II, de Herder WW, et al: Paraneoplastic syndromes secondary to neuroendocrine tumours. Endocr Relat Cancer 2010;17:R173-R193.

$>8$ Jensen RT, Niederle B, Mitry E, et al: Gastrinoma (duodenal and pancreatic). Neuroendocrinology 2006;84:173-182.
-9 Ellison EC, Johnson JA: The Zollinger-Ellison syndrome: a comprehensive review of historical, scientific, and clinical considerations. Curr Probl Surg 2009;46:13-106.

10 Roy P, Venzon DJ, Shojamanesh H, et al: Zollinger-Ellison syndrome: clinical presentation in 261 patients. Medicine (Baltimore) 2000;79:379-411.

11 Jensen RT, Berna MJ, Bingham MD, et al: Inherited pancreatic endocrine tumor syndromes: advances in molecular pathogenesis, diagnosis, management and controversies. Cancer 2008;113(suppl):1807-1843.

12 Gibril F, Schumann M, Pace A, et al: Multiple endocrine neoplasia type 1 and ZollingerEllison syndrome. A prospective study of 107 cases and comparison with 1,009 patients from the literature. Medicine (Baltimore) 2004;83:43-83.

13 Vanderveen K, Grant C: Insulinoma. Cancer Treat Res 2010;153:235-252.

14 Guettier JM, Gorden P: Insulin secretion and insulin-producing tumors. Expert Rev Endocrinol Metab 2010;5:217-227.

15 De Herder WW, Niederle B, Scoazec JY, et al: Well-differentiated pancreatic tumor/carcinoma: insulinoma. Neuroendocrinology 2006;84:183-188.
16 Anlauf M, Garbrecht N, Henopp T, et al: Sporadic versus hereditary gastrinomas of the duodenum and pancreas: distinct clinicopathological and epidemiological features. World J 2006;12:5440-5446.

17 Kloppel G, Anlauf M: Gastrinoma - morphological aspects. Wien Klin Wochenschr 2007; 119:579-584.

18 Gibril F, Jensen RT: Advances in evaluation and management of gastrinoma in patients with Zollinger-Ellison syndrome. Curr Gastroenterol Rep 2005; 7:114-121.

19 Anlauf M, Perren A, Meyer CL, et al: Precursor lesions in patients with multiple endocrine neoplasia type 1 associated duodenal gastrinomas. Gastroenterology 2005;128: 1187-1198.

20 Bosman FT, Carneiro F, Hruban RH, Theise ND: World Health Organization classification of tumors and genetics of the digestive system, ed 1. Lyon, IARC, 2010.

21 Rindi G, Kloppel G, Alhman H, et al: TNM staging of foregut (neuro)endocrine tumors: a consensus proposal including a grading system. Virchows Arch 2006;449:395-401.

22 Edge SB, Byrd DR, Compton CC, Fritz AG, Greene FL, Trotti A: AJCC Cancer Staging Manual, ed 1. New York, Springer, 2010. 
-23 Fischer L, Kleeff J, Esposito I, et al: Clinical outcome and long-term survival in 118 consecutive patients with neuroendocrine tumours of the pancreas. Br J Surg 2008;95: 627-635.

24 Ekeblad S, Skogseid B, Dunder K, et al: Prognostic factors and survival in 324 patients with pancreatic endocrine tumor treated at a single institution. Clin Cancer Res 2008; 14 : 7798-7803.

25 Pape UF, Jann H, Muller-Nordhorn J, et al: Prognostic relevance of a novel TNM classification system for upper gastroenteropancreatic neuroendocrine tumors. Cancer 2008;113:256-265.

26 Zhao YP, Zhan HX, Zhang TP, et al: Surgical management of patients with insulinomas: result of 292 cases in a single institution. J Surg Oncol 2011;103:169-174.

27 Casadei R, Ricci C, Rega D, et al: Pancreatic endocrine tumors less than $4 \mathrm{~cm}$ in diameter: resect or enucleate? A single-center experience. Pancreas 2010;39:825-828.

28 Zerbi A, Falconi M, Rindi G, et al: Clinicopathological features of pancreatic endocrine tumors: a prospective multicenter study in Italy of 297 sporadic cases. Am J Gastroenterol 2010;105:1421-1429.

29 Niederle MB, Hackl M, Kaserer K, et al: Gastroenteropancreatic neuroendocrine tumours: the current incidence and staging based on the WHO and European Neuroendocrine Tumour Society classification: an analysis based on prospectively collected parameters. Endocr Relat Cancer 2010;17:909918.

- 30 Klimstra DS, Modlin IR, Coppola D, et al: The pathologic classification of neuroendocrine tumors: a review of nomenclature, grading, and staging systems. Pancreas 2010; 39:707-712.

31 Weber HC, Venzon DJ, Lin JT, et al: Determinants of metastatic rate and survival in patients with Zollinger-Ellison syndrome: a prospective long-term study. Gastroenterology 1995;108:1637-1649.

-32 Banasch M, Schmitz F. Diagnosis and treatment of gastrinoma in the era of proton pump inhibitors. Wien Klin Wochenschr 2007;119:573-578

33 Thom AK, Norton JA, Axiotis CA, et al: Location, incidence and malignant potential of duodenal gastrinomas. Surgery 1991;110: 1086-1093.

34 Stabile BE, Morrow DJ, Passaro E Jr: The gastrinoma triangle: operative implications. Am J Surg 1984;147:25-31.

- 35 Pipeleers-Marichal M, Kloppel G: Gastrinomas in MEN-1. N Engl J Med 1990;323:349.

- 36 MacFarlane MP, Fraker DL, Alexander HR, et al: A prospective study of surgical resection of duodenal and pancreatic gastrinomas in multiple endocrine neoplasia type 1 . Surgery 1995;118:973-980.

- 37 Garbrecht N, Anlauf M, Schmitt A, et al: Somatostatin-producing neuroendocrine tumors of the duodenum and pancreas: inci- dence, types, biological behavior, association with inherited syndromes, and functional activity. Endocr Relat Cancer 2008;15:229241.

38 Isidori AM, Kaltsas GA, Grossman AB: Ectopic ACTH syndrome. Front Horm Res 2006;35:143-156.

39 Hoffmann KM, Furukawa M, Jensen RT: Duodenal neuroendocrine tumors: classification, functional syndromes, diagnosis and medical treatment. Best Pract Res Clin Gastroenterol 2005; 19:675-697.

40 Levy-Bohbot N, Merle C, Goudet P, et al: Prevalence, characteristics and prognosis of MEN-1-associated glucagonomas, VIPomas, and somatostatinomas: study from the GTE (Groupe des Tumeurs Endocrines) registry. Gastroenterol Clin Biol 2004;28:10751081.

41 Yu F, Venzon DJ, Serrano J, et al: Prospective study of the clinical course, prognostic factors and survival in patients with longstanding Zollinger-Ellison syndrome. J Clin Oncol 1999;17:615-630.

42 Jensen RT: Natural history of digestive endocrine tumors; in Mignon M, Colombel JF (eds): Recent Advances in Pathophysiology and Management of Inflammatory Bowel Diseases and Digestive Endocrine Tumors. Paris, Libbey Eurotext, 1999, pp 192-219.

43 Gibril F, Venzon DJ, Ojeaburu JV, et al: Prospective study of the natural history of gastrinoma in patients with MEN1: definition of an aggressive and a nonaggressive form. J Clin Endocrinol Metab 2001;86:5282-5293.

44 Jensen RT: Zollinger-Ellison syndrome; in Doherty GM, Skogseid B (eds): Surgical Endocrinology: Clinical Syndromes. Philadelphia, Lippincott Williams \& Wilkins, 2001, pp 291-344.

45 Maton PN, Gardner JD, Jensen RT: Cushing's syndrome in patients with Zollinger-Ellison syndrome. N Engl J Med 1986;315:1-5.

46 Cadiot G, Vuagnat A, Doukhan I, et al: Prognostic factors in patients with Zollinger-Ellison syndrome and multiple endocrine neoplasia type 1. Gastroenterology 1999;116: 286-293.

47 Norton JA, Jensen RT: Resolved and unresolved controversies in the surgical management of patients with Zollinger-Ellison syndrome. Ann Surg 2004;240:757-773.

48 Goh BK, Chow PK, Tan YM, et al: Validation of five contemporary prognostication systems for primary pancreatic endocrine neoplasms: results from a single institution experience with 61 surgically treated cases. ANZ J Surg 2011;81:79-85.

49 London JF, Shawker TH, Doppman JL, et al: Zollinger-Ellison syndrome: prospective assessment of abdominal US in the localization of gastrinomas. Radiology 1991;178:763-767.

50 Mathur A, Gorden P, Libutti SK: Insulinoma. Surg Clin North Am 2009;89:1105-1121.

-51 Jonkers YM, Claessen SM, Perren A, et al: DNA copy number status is a powerful predictor of poor survival in endocrine pancre- atic tumor patients. Endocr Relat Cancer 2007;14:769-779.

52 Norton JA, Fang TD, Jensen RT: Surgery for gastrinoma and insulinoma in multiple endocrine neoplasia type 1. J Natl Compr Cancer 2006;4:148-153.

-53 Goudet P, Murat A, Cardot-Bauters C, et al: Thymic neuroendocrine tumors in multiple endocrine neoplasia type 1: a comparative study on 21 cases among a series of 761 MEN1 from the GTE (Groupe des Tumeurs Endocrines). World J Surg 2009;33:11971207.

54 Goudet P, Murat A, Binquet C, et al: Risk factors and causes of death in MEN1 disease. A GTE (Groupe d'Etude des Tumeurs Endocrines) cohort study among 758 patients. World J Surg 2010;34:249-255.

- 55 Gibril F, Chen Y-J, Schrump DS, et al: Prospective study of thymic carcinoids in patients with multiple endocrine neoplasia type 1. J Clin Endocrinol Metab 2003;88: 1066-1081.

-56 Krenning EP, Bakker WH, Kooij PP, et al: Somatostatin receptor scintigraphy with indium-111-DTPA-D-Phe ${ }^{1}$-octreotide in man: metabolism, dosimetry and comparison with iodine-123-Tyr-3-octreotide. J Nucl Med 1992;33:652-658.

57 Osefo N, Ito T, Jensen RT: Gastric acid hypersecretory states: recent insights and advances. Curr Gastroenterol Rep 2009;11:433-441.

58 Berna MJ, Hoffmann KM, Serrano J, et al: Serum gastrin in Zollinger-Ellison syndrome. I. Prospective study of fasting serum gastrin in 309 patients from the National Institutes of Health and comparison with 2,229 cases from the literature. Medicine (Baltimore) 2006;85:295-330.

59 Corleto VD, Annibale B, Gibril F, et al: Does the widespread use of proton pump inhibitors mask, complicate and/or delay the diagnosis of Zollinger-Ellison syndrome? Aliment Pharmacol Ther 2001;15:1555-1561.

60 Arnold R: Diagnosis and differential diagnosis of hypergastrinemia. Wien Klin Wochenschr 2007;119:564-569.

-61 Roy P, Venzon DJ, Feigenbaum KM, et al: Gastric secretion in Zollinger-Ellison syndrome: correlation with clinical expression, tumor extent and role in diagnosis - a prospective NIH study of 235 patients and review of the literature in 984 cases. Medicine (Baltimore) 2001;80:189-222.

62 Benya RV, Metz DC, Venzon DJ, et al: Zollinger-Ellison syndrome can be the initial endocrine manifestation in patients with multiple endocrine neoplasia type 1 . Am J Med 1994;97:436-444.

63 Cadiot G, Houillier P, Allouch A, et al: Oral calcium tolerance test in the early diagnosis of primary hyperparathyroidism and multiple endocrine neoplasia type 1 in patients with the Zollinger-Ellison syndrome. Groupe de Recherche et d'Etude du Syndrome de Zollinger-Ellison. Gut 1996;39: 273-278. 
64 Wynick D, Williams SJ, Bloom SR: Symptomatic secondary hormone syndromes in patients with established malignant pancreatic endocrine tumors. N Engl J Med 1988; 319:605-607.

65 Chiang HC, O’Dorisio TM, Huang SC, et al: Multiple hormone elevations in patients with Zollinger-Ellison syndrome: prospective study of clinical significance and of the development of a second symptomatic pancreatic endocrine tumor syndrome. Gastroenterology 1990;99:1565-1575.

66 Vinik AI, Woltering EA, Warner RR, et al: NANETS consensus guidelines for the diagnosis of neuroendocrine tumor. Pancreas 2010;39:713-734.

67 O’Toole D, Grossman A, Gross D, et al: ENETS consensus guidelines for the standards of care in neuroendocrine tumors: biochemical markers. Neuroendocrinology 2009;90: 194-202.

68 Rehfeld JF, Gingras MH, Bardram L, et al: The Zollinger-Ellison syndrome and mismeasurement of gastrin. Gastroenterology 2011;140:1444-1453.

-69 Weber HC, Venzon DJ, Jensen RT, et al: Studies on the interrelation between ZollingerEllison syndrome, Helicobacter pylori and proton pump inhibitor therapy. Gastroenterology 1997;112:84-91

70 Jensen RT: Consequences of long-term proton pump blockade: highlighting insights from studies of patients with gastrinomas. Basic Clin Pharmacol Toxicol 2006;98:4-19.

71 Oh DS, Wang HS, Ohning GV, et al: Validation of a new endoscopic technique to assess acid output in Zollinger-Ellison syndrome. Clin Gastroenterol Hepatol 2006;4:14671473.

72 Berna MJ, Hoffmann KM, Long SH, et al: Serum gastrin in Zollinger-Ellison syndrome. II. Prospective study of gastrin provocative testing in 293 patients from the National Institutes of Health and comparison with 537 cases from the literature. Evaluation of diagnostic criteria, proposal of new criteria, and correlations with clinical and tumoral features. Medicine (Baltimore) 2006;85:331364.

73 Mignon M, Jais P, Cadiot G, Yedder D, Vatier $\mathrm{J}$ : Clinical features and advances in biological diagnostic criteria for Zollinger-Ellison syndrome; in Mignon M, Jensen RT (eds): Endocrine Tumors of the Pancreas: Recent Advances in Research and Management. Series. Front Gastrointest Res. Basel, Karger, 1995, vol 23, pp 223-239.

74 Frucht H, Howard JM, Slaff JI, et al: Secretin and calcium provocative tests in the Zollinger-Ellison syndrome: a prospective study. Ann Intern Med 1989;111:713-722.

75 Gibril F, Jensen RT: Zollinger-Ellison syndrome revisited: diagnosis, biologic markers, associated inherited disorders, and acid hypersecretion. Curr Gastroenterol Rep $2004 ; 6: 454-463$.
76 Goldman JA, Blanton WP, Hay DW, et al: Case report: false-positive secretin stimulation test for gastrinoma associated with the use of proton pump inhibitor therapy. Clin Gastroenterol Hepatol 2009;7:600-602.

77 Niederle B: Hypergastrinemia - diagnosis and treatment. Wien Klin Wochenschr 2007; 119:561-563.

78 De Herder WW, O’Toole D, Rindi G, et al: ENETS consensus guidelines for the management of patients with digestive neuroendocrine tumors. Part 1. Stomach, duodeneum and pancreas. Neuroendocrinology 2006;84:151-216.

79 Berna MJ, Annibale B, Marignani M, et al: A prospective study of gastric carcinoids and enterochromaffin-like cells changes in multiple endocrine neoplasia type 1 and Zollinger-Ellison syndrome: identification of risk factors. J Clin Endocrinol Metab 2008; 93:1582-1591.

80 Norton JA, Cornelius MJ, Doppman JL, et al: Effect of parathyroidectomy in patients with hyperparathyroidism, Zollinger-Ellison syndrome and multiple endocrine neoplasia type I: a prospective study. Surgery 1987;102: 958-966.

81 Waldmann J, Fendrich V, Habbe N, et al: Screening of patients with multiple endocrine neoplasia type 1 (MEN-1): a critical analysis of its value. World J Surg 2009;33: 1208-1218.

82 Norton JA, Venzon DJ, Berna MJ, et al: Prospective study of surgery for primary hyperaparathyroidism in multiple endocrine neoplasia type 1, and Zollinger-Ellison syndrome: long-term outcome of a more virulent form of HPT. Ann Surg 2008;247:501-510.

83 Jensen RT: Management of the Zollinger-Ellison syndrome in patients with multiple endocrine neoplasia type 1. J Intern Med 1998; 243:477-488.

84 Brandi ML, Gagel RF, Angeli A, et al: Guidelines for diagnosis and therapy of MEN type 1 and type 2. J Clin Endocrinol Metab 2001; 86:5658-5671.

85 Thakker RV: Multiple endocrine neoplasia type 1 (MEN1). Best Pract Res Clin Endocrinol Metab 2010;24:355-370.

86 Service FJ, Natt N, Thompson GB, et al: Noninsulinoma pancreatogenous hypoglycemia: a novel syndrome of hyperinsulinemic hypoglycemia in adults independent of mutations in Kir6.2 and SUR1 genes. J Clin Endocrinol Metab 1999;84:1582-1589.

87 Marsk R, Jonas E, Rasmussen F, et al: Nationwide cohort study of post-gastric bypass hypoglycaemia including 5,040 patients undergoing surgery for obesity in 1986-2006 in Sweden. Diabetologia 2010;53:2307-2311.

88 Patti ME, Goldfine AB: Hypoglycaemia following gastric bypass surgery - diabetes remission in the extreme? Diabetologia 2010; $53: 2276-2279$
89 Van Bon AC, Benhadi N, Endert E, et al: Evaluation of endocrine tests. D: the prolonged fasting test for insulinoma. Neth J Med 2009;67:274-278.

90 Hirshberg B, Livi A, Bartlett DL, et al: Forty-eight-hour fast: the diagnostic test for insulinoma. J Clin Endocrinol Metab 2000; $85: 3222-3226$

91 Vezzosi D, Bennet A, Fauvel J, et al: Insulin, C-peptide and proinsulin for the biochemical diagnosis of hypoglycaemia related to endogenous hyperinsulinism. Eur J Endocrinol 2007; 157:75-83.

92 Sundin A, Vullierme MP, Kaltsas G, et al: ENETS guidelines for the standards of care in patients with neuroendocrine tumours: radiological examinations in patients with neuroendocrine tumours. Neuroendocrinology 2009;90:183.

93 Kwekkeboom DJ, Krenning EP, Scheidhauer K, et al: ENETS consensus guidelines for the standards of care in neuroendocrine tumors: somatostatin receptor imaging with ${ }^{111}$ In-pentetreotide. Neuroendocrinology 2009;90:184-189.

-94 Sundin A, Garske U, Orlefors H: Nuclear imaging of neuroendocrine tumours. Best Pract Res Clin Endocrinol Metab 2007;21:69-85.

$\checkmark 95$ Rockall AG, Reznek RH: Imaging of neuroendocrine tumours (CT/MR/US). Best Pract Res Clin Endocrinol Metab 2007;21:43-68.

$\$ 96$ Morrow EH, Norton JA: Surgical management of Zollinger-Ellison syndrome; state of the art. Surg Clin North Am 2009;89: 1091-1103.

97 Fraker DL, Norton JA, Alexander HR, et al: Surgery in Zollinger-Ellison syndrome alters the natural history of gastrinoma. Ann Surg 1994;220:320-330.

$>98$ Norton JA, Fraker DL, Alexander HR, et al: Surgery increases survival in patients with gastrinoma. Ann Surg 2006;244:410-419.

$\checkmark 99$ Norton JA, Alexander HR, Fraker DL, et al: Does the use of routine duodenotomy (DUODX) affect rate of cure, development of liver metastases or survival in patients with Zollinger-Ellison syndrome? Ann Surg 2004;239:617-626.

100 Lebtahi R, Cadiot G, Sarda L, et al: Clinical impact of somatostatin receptor scintigraphy in the management of patients with neuroendocrine gastroenteropancreatic tumors. J Nucl Med 1997;38:853-858.

101 Doppman JL, Miller DL, Chang R, et al: Gastrinomas: localization by means of selective intraarterial injection of secretin. Radiology 1990;174:25-29.

102 Termanini B, Gibril F, Reynolds JC, et al: Value of somatostatin receptor scintigraphy: a prospective study in gastrinoma of its effect on clinical management. Gastroenterology 1997;112:335-347.

103 Alexander HR, Fraker DL, Norton JA, et al: Prospective study of somatostatin receptor scintigraphy and its effect on operative outcome in patients with Zollinger-Ellison syndrome. Ann Surg 1998;228:228-238. 
104 Anderson MA, Carpenter S, Thompson NW, et al: Endoscopic ultrasound is highly accurate and directs management in patients with neuroendocrine tumors of the pancreas. Am J Gastroenterol 2000;95: 2271-2277.

-105 Ruszniewski P, Amouyal P, Amouyal G, et al: Localization of gastrinomas by endoscopic ultrasonography in patients with Zollinger-Ellison syndrome. Surgery 1995; 117:629-635.

106 Patel KK, Kim MK: Neuroendocrine tumors of the pancreas: endoscopic diagnosis. Curr Opin Gastroenterol 2008;24:638642 .

107 Guettier JM, Kam A, Chang R, et al: Localization of insulinomas to regions of the pancreas by intraarterial calcium stimulation: the NIH experience. J Clin Endocrinol Metab 2009;94:1074-1080.

108 Morganstein DL, Lewis DH, Jackson J, et al: The role of arterial stimulation and simultaneous venous sampling in addition to cross-sectional imaging for localisation of biochemically proven insulinoma. Eur Radiol 2009;19:2467-2473.

109 Gibril F, Reynolds JC, Doppman JL, et al: Somatostatin receptor scintigraphy: its sensitivity compared with that of other imaging methods in detecting primary and metastatic gastrinomas: a prospective study. Ann Intern Med 1996;125:26-34.

-110 Gibril F, Jensen RT: Diagnostic uses of radiolabelled somatostatin-receptor analogues in gastroenteropancreatic endocrine tumors. Dig Liver Dis 2004;36:S106S120.

-111 Akerstrom G, Hellman P: Surgery on neuroendocrine tumours. Best Pract Res Clin Endocrinol Metab 2007;21:87-109.

-112 Srirajaskanthan R, Kayani I, Quigley AM, et al: The role of ${ }^{68} \mathrm{Ga}$-DOTATATE PET in patients with neuroendocrine tumors and negative or equivocal findings on ${ }^{111}$ In-DTPA-octreotide scintigraphy. J Nucl Med 2010;51:875-882.

-113 Putzer D, Gabriel M, Henninger B, et al: Bone metastases in patients with neuroendocrine tumor: ${ }^{68} \mathrm{Ga}$-DOTA-Tyr ${ }^{3}$-octreotide PET in comparison to $\mathrm{CT}$ and bone scintigraphy. J Nucl Med 2009;50:12141221.

-114 Ambrosini V, Nanni C, Zompatori M, et al: ${ }^{68} \mathrm{Ga}$-DOTA-NOC PET/CT in comparison with CT for the detection of bone metastasis in patients with neuroendocrine tumours. Eur J Nucl Med Mol Imaging 2010; 37:722-727.

-115 Dudczak R, Traub-Weidinger T: PET and PET/CT in endocrine tumours. Eur J Radiol 2010;73:481-493.

-116 Buchmann I, Henze M, Engelbrecht S, et al: Comparison of ${ }^{68} \mathrm{Ga}$-DOTATOC PET and ${ }^{111}$ In-DTPAOC (Octreoscan) SPECT in patients with neuroendocrine tumours. Eur J Nucl Med Mol Imaging 2007;34:16171626.
117 Gabriel M, Decristoforo C, Kendler D, et al: ${ }^{68} \mathrm{Ga}$-DOTA-Tyr ${ }^{3}$-octreotide PET in neuroendocrine tumors: comparison with somatostatin receptor scintigraphy and CT. J Nucl Med 2007;48:508-518.

118 Ruf J, Heuck F, Schiefer J, et al: Impact of multiphase ${ }^{68} \mathrm{Ga}$-DOTATOC-PET/CT on therapy management in patients with neuroendocrine tumors. Neuroendocrinology 2010;91:101-109.

119 Cadiot G, Lebtahi R, Sarda L, et al: Preoperative detection of duodenal gastrinomas and peripancreatic lymph nodes by somatostatin receptor scintigraphy. Gastroenterology 1996;111:845-854.

120 Dromain C, De Baere T, Lumbroso J, et al: Detection of liver metastases from endocrine tumors: a prospective comparison of somatostatin receptor scintigraphy, computed tomography, and magnetic resonance imaging. J Clin Oncol 2005;23:70-78.

121 Gibril F, Doppman JL, Reynolds JC, et al: Bone metastases in patients with gastrinomas: a prospective study of bone scanning, somatostatin receptor scanning, and MRI in their detection, their frequency, location and effect of their detection on management. J Clin Oncol 1998;16:1040-1053.

122 Lebtahi R, Cadiot G, Delahaye N, et al: Detection of bone metastases in patients with endocrine gastroenteropancreatic tumors: bone scintigraphy compared with somatostatin receptor scintigraphy. J Nucl Med 1999;40:1602-1608.

123 Bhate K, Mok WY, Tran K, et al: Functional assessment in the multimodality imaging of pancreatic neuroendocrine tumours. Minerva Endocrinol 2010;35:17-25.

124 Thomas-Marques L, Murat A, Delemer B, et al: Prospective endoscopic ultrasonographic evaluation of the frequency of nonfunctioning pancreaticoduodenal endocrine tumors in patients with multiple endocrine neoplasia type 1. Am J Gastroenterol 2006;101:266-273.

125 Triponez F, Goudet P, Dosseh D, et al: Is surgery beneficial for MEN1 patients with small $(<$ or $=2 \mathrm{~cm})$, nonfunctioning pancreaticoduodenal endocrine tumor? An analysis of 65 patients from the GTE. World J Surg 2006;30:654-662.

126 Figueiredo FA, Giovannini M, Monges G, et al: Pancreatic endocrine tumors: a large single-center experience. Pancreas 2009; 38:936-940.

127 Christ E, Wild D, Forrer F, et al: Glucagonlike peptide-1 receptor imaging for localization of insulinomas. J Clin Endocrinol Metab 2009;94:4398-4405.

-128 Kauhanen S, Seppanen M, Minn H, et al: Clinical PET imaging of insulinoma and $\beta$ cell hyperplasia. Curr Pharm Des 2010;16: 1550-1560.

129 Chetty R: An overview of practical issues in the diagnosis of gastroenteropancreatic neuroendocrine pathology. Arch Pathol Lab Med 2008;132:1285-1289.
130 Kloppel G: Tumour biology and histopathology of neuroendocrine tumours. Best Pract Res Clin Endocrinol Metab 2007;21: 15-31.

131 Kloppel G, Couvelard A, Perren A, et al: ENETS guidelines for the standards of care in patients with neuroendocrine tumors: towards a standardized approach to the diagnosis of gastroenteropancreatic neuroendocrine tumors and their prognostic stratification. Neuroendocrinology 2009;90:166.

132 Capelli P, Martignoni G, Pedica F, et al: Endocrine neoplasms of the pancreas: pathologic and genetic features. Arch Pathol Lab Med 2009;133:350-364.

133 Schmitt AM, Anlauf M, Rousson V, et al: WHO 2004 criteria and CK19 are reliable prognostic markers in pancreatic endocrine tumors. Am J Surg Pathol 2007;31: 1677-1682.

134 Scarpa A, Mantovani W, Capelli P, et al: Pancreatic endocrine tumors: improved TNM staging and histopathological grading permit a clinically efficient prognostic stratification of patients. Mod Pathol 2010; 23:824-833.

135 La Rosa S, Klersy C, Uccella S, et al: Improved histologic and clinicopathologic criteria for prognostic evaluation of pancreatic endocrine tumors. Hum Pathol 2009;40:30-40.

136 Casadei R, Ricci C, Pezzilli R, et al: Value of both WHO and TNM classification systems for patients with pancreatic endocrine tumors: results of a single-center series. World J Surg 2009;33:2458-2463.

137 Klimstra DS, Modlin IR, Adsay NV, et al: Pathology reporting of neuroendocrine tumors: application of the Delphic consensus process to the development of a minimum pathology data set. Am J Surg Pathol 2010; 34:300-313.

138 Walker FM, Lehy T, Bernuau DG, et al: Detection of gastrin mRNA in human antral mucosa and digestive endocrine tumors by in situ hybridization: a correlative study with immunocytochemistry and electron microscopy. J Histochem Cytochem 1992; 40:1363-1372.

139 Toumpanakis CG, Caplin ME: Molecular genetics of gastroenteropancreatic neuroendocrine tumors. Am J Gastroenterol 2008;103:729-732.

140 Anlauf M, Bauersfeld J, Raffel A, et al: Insulinomatosis: a multicentric insulinoma disease that frequently causes early recurrent hyperinsulinemic hypoglycemia. Am J Surg Pathol 2009;33:339-346.

$>141$ Henopp T, Anlauf M, Schmitt A, et al: Glucagon cell adenomatosis: a newly recognized disease of the endocrine pancreas. J Clin Endocrinol Metab 2009;94:213217.

142 Fendrich V, Waldmann J, Bartsch DK, et al: Surgical management of pancreatic endocrine tumors. Nat Rev Clin Oncol 2009;6: 419-428. 
143 Zerbi A, Capitanio V, Boninsegna L, et al: Surgical treatment of pancreatic endocrine tumours in Italy: results of a prospective multicentre study of 262 cases. Langenbecks Arch Surg 2011;396:313-321.

144 Abood GJ, Go A, Malhotra D, et al: The surgical and systemic management of neuroendocrine tumors of the pancreas. Surg Clin North Am 2009;89:249-266, x.

145 Lorenz K, Dralle H: Surgical treatment of sporadic gastrinoma. Wien Klin Wochenschr 2007;119:597-601.

146 Bartsch DK, Langer P, Rothmund M: Surgical aspects of gastrinoma in multiple endocrine neoplasia type 1 . Wien Klin Wochenschr 2007;119:602-608.

-147 Norton JA, Fraker DL, Alexander HR, et al: Surgery to cure the Zollinger-Ellison syndrome. N Engl J Med 1999;341:635-644.

-148 Tonelli F, Fratini G, Nesi G, et al: Pancreatectomy in multiple endocrine neoplasia type 1-related gastrinomas and pancreatic endocrine neoplasias. Ann Surg 2006;244: 61-70.

-149 Norton JA, Alexander HR, Fraker DL, et al: Comparison of surgical results in patients with advanced and limited disease with multiple endocrine neoplasia type 1 and Zollinger-Ellison syndrome. Ann Surg 2001;234:495-506.

-150 Franz RC, Penzhorn HO: Is total gastrectomy still a viable option in the management of patients with the Zollinger-Ellison syndrome? S Afr J Surg 2007;45:58-60.

-151 Fishbeyn VA, Norton JA, Benya RV, et al: Assessment and prediction of long-term cure in patients with Zollinger-Ellison syndrome: the best approach. Ann Intern Med 1993;119:199-206.

-152 Steinmuller T, Kianmanesh R, Falconi M, et al: Consensus guidelines for the management of patients with liver metastases from digestive (neuro)endocrine tumors: foregut, midgut, hindgut, and unknown primary. Neuroendocrinology 2008;87:47-62.

153 Sugg SL, Norton JA, Fraker DL, et al: A prospective study of intraoperative methods to diagnose and resect duodenal gastrinomas. Ann Surg 1993;218:138-144.

-154 Grobmyer SR, Vogel SB, McGuigan JE, et al: Reoperative surgery in sporadic ZollingerEllison Syndrome: long-term results. J Am Coll Surg 2009;208:718-722.

-155 Norton JA, Alexander HA, Fraker DL, et al: Possible primary lymph node gastrinomas: occurrence, natural history and predictive factors: a prospective study. Ann Surg 2003; 237:650-659.

156 Norton JA, Jensen RT: Role of surgery in Zollinger-Ellison syndrome. J Am Coll Surg 2007;205:S34-S37.

-157 Fendrich V, Langer P, Waldmann J, et al: Management of sporadic and multiple endocrine neoplasia type 1 gastrinomas. $\mathrm{Br} J$ Surg 2007;94:1331-1341.
158 Fernandez-Cruz L, Blanco L, Cosa R, et al: Is laparoscopic resection adequate in patients with neuroendocrine pancreatic tumors? World J Surg 2008;32:904-917.

159 Espana-Gomez MN, Velazquez-Fernandez D, Bezaury P, et al: Pancreatic insulinoma: a surgical experience. World J Surg 2009;33: 1966-1970.

160 Richards ML, Thompson GB, Farley DR, et al: Setting the bar for laparoscopic resection of sporadic insulinoma. World J Surg 2011;35:785-789.

161 Isla A, Arbuckle JD, Kekis PB, et al: Laparoscopic management of insulinomas. Br J Surg 2009;96:185-190.

162 Krudy AG, Doppman JL, Jensen RT, et al: Localization of islet cell tumors by dynamic CT: comparison with plain CT, arteriography, sonography and venous sampling. Am J Roentgenol 1984;143:585-589.

163 Gimm O, Konig E, Thanh PN, et al: Intraoperative quick insulin assay to confirm complete resection of insulinomas guided by selective arterial calcium injection. Langenbecks Arch Surg 2007;392:679-684.

164 Elias D, Goere D, Leroux G, et al: Combined liver surgery and RFA for patients with gastroenteropancreatic endocrine tumors presenting with more than 15 metastases to the liver. Eur J Surg Oncol 2009;35:1092-1097.

165 Fendrich V, Michl P, Habbe N, et al: Liverspecific therapies for metastases of neuroendocrine pancreatic tumors. World J Hepatol 2010;2:367-373.

166 Kianmanesh R, Sauvanet A, Hentic O, et al: Two-step surgery for synchronous bilobar liver metastases from digestive endocrine tumors: a safe approach for radical resection. Ann Surg 2008;247:659-665.

167 Hodul P, Malafa M, Choi J, et al: The role of cytoreductive hepatic surgery as an adjunct to the management of metastatic neuroendocrine carcinomas. Cancer Control 2006; 13:61-71.

168 Desai KK, Khan MS, Toumpanakis C, et al: Management of gastroenteropancreatic neuroendocrine tumors (GEP-NETs). Minerva Gastroenterol Dietol 2009;55:425443.

169 Reddy SK, Clary BM: Neuroendocrine liver metastases. Surg Clin North Am 2010;90: 853-861.

170 Akyildiz HY, Mitchell J, Milas M, et al: Laparoscopic radiofrequency thermal ablation of neuroendocrine hepatic metastases: long-term follow-up. Surgery 2010;148: 1288-1293.

171 Modlin IM, Pavel M, Kidd M, et al: Review article: somatostatin analogues in the treatment of gastroenteropancreatic neuroendocrine (carcinoid) tumours. Aliment Pharmacol Ther 2010;31:169-188.

172 Nieto JM, Pisegna JR: The role of proton pump inhibitors in the treatment of Zollinger-Ellison syndrome. Expert Opin Pharmacother 2006;7:169-175.
173 Auernhammer CJ, Goke B: Medical treatment of gastrinomas. Wien Klin Wochenschr 2007;119:609-615.

174 Baldwin CM, Keam SJ: Rabeprazole: a review of its use in the management of gastric acid-related diseases in adults. Drugs 2009; 69:1373-1401.

175 Wilcox CM, Hirschowitz BI: Treatment strategies for Zollinger-Ellison syndrome. Expert Opin Pharmacother 2009;10:11451157.

176 Metz DC, Sostek MB, Ruszniewski P, et al: Effects of esomeprazole on acid output in patients with Zollinger-Ellison syndrome or idiopathic gastric acid hypersecretion. Am J Gastroenterol 2007;102:2648-2654.

$\checkmark 177$ Morocutti A, Merrouche M, Bjaaland T, et al: An open-label study of rabeprazole in patients with Zollinger-Ellison syndrome or idiopathic gastric acid hypersecretion. Aliment Pharmacol Ther 2006;24:14391444.

178 Metz DC, Comer GM, Soffer E, et al: Threeyear oral pantoprazole administration is effective for patients with Zollinger-Ellison syndrome and other hypersecretory conditions. Aliment Pharmacol Ther 2006;23: 437-444.

179 Yang YX, Metz DC: Safety of proton pump inhibitor exposure. Gastroenterology 2010; 139:1115-1127.

180 Ito T, Jensen RT: Association of long-term proton pump inhibitor therapy with bone fractures and effects on absorption of calcium, vitamin $\mathrm{B}_{12}$, iron, and magnesium. Curr Gastroenterol Rep 2010;12:448-457.

181 Termanini B, Gibril F, Sutliff VE III, et al: Effect of long-term gastric acid suppressive therapy on serum vitamin $B_{12}$ levels in patients with Zollinger-Ellison syndrome. Am J Med 1998;104:422-430.

182 Ojeaburu JV, Ito T, Crafa P, et al: Mechanism of acid hypersecretion post-curative gastrinoma resection. Dig Dis Sci 2011;56: 139-154.

183 Pisegna JR, Norton JA, Slimak GG, et al: Effects of curative resection on gastric secretory function and antisecretory drug requirement in the Zollinger-Ellison syndrome. Gastroenterology 1992; 102: 767-778.

184 Maton PN, Frucht H, Vinayek R, et al: Medical management of patients with ZollingerEllison syndrome who have had previous gastric surgery: a prospective study. Gastroenterology 1988;94:294-299.

185 Vezzosi D, Bennet A, Rochaix P, et al: Octreotide in insulinoma patients: efficacy on hypoglycemia, relationships with Octreoscan scintigraphy and immunostaining with anti-sst2A and anti-sst 5 antibodies. Eur J Endocrinol 2005;152:757-767.

186 Kulke MH, Bergsland EK, Yao JC: Glycemic control in patients with insulinoma treated with everolimus. N Engl J Med 2009;360: 195-197. 
187 Bourcier ME, Sherrod A, DiGuardo M, et al: Successful control of intractable hypoglycemia using rapamycin in an 86-yearold man with a pancreatic insulin-secreting islet cell tumor and metastases. J Clin Endocrinol Metab 2009;94:3157-3162.

188 Ong GS, Henley DE, Hurley D, et al: Therapies for the medical management of persistent hypoglycaemia in two cases of inoperable malignant insulinoma. Eur J Endocrinol 2010;162:1001-1008.

189 Oberg K, Kvols L, Caplin M, et al: Consensus report on the use of somatostatin analogs for the management of neuroendocrine tumors of the gastroenteropancreatic system. Ann Oncol 2004;15:966-973.

190 Fazio N, de Braud F, Delle Fave G, et al: Interferon- $\alpha$ and somatostatin analog in patients with gastroenteropancreatic neuroendocrine carcinoma: single agent or combination? Ann Oncol 2007;18:13-19.

191 Petrossians P, Thonnard AS, Beckers A: Medical treatment in Cushing's syndrome: dopamine agonists and cabergoline. Neuroendocrinology 2010;92(suppl 1):116-119.

192 Castinetti F, Conte-Devolx B, Brue T: Medical treatment of Cushing's syndrome: glucocorticoid receptor antagonists and $\mathrm{mi}$ fepristone. Neuroendocrinology 2010; 92(suppl 1):125-130.

- 193 Pivonello R, Ferone D, Lamberts SW, et al: Cabergoline plus lanreotide for ectopic Cushing's syndrome. N Engl J Med 2005; 352:2457-2458.

194 Feelders RA, Hofland LJ, de Herder WW: Medical treatment of Cushing's syndrome: adrenal-blocking drugs and ketaconazole. Neuroendocrinology 2010;92(suppl 1):111115.

195 Pavel M, Baudin E, Couvelard A, Krenning E, Öberg K, Steinmüller T, et al: ENETS consensus guidelines for the management of patients with liver and other distant metastases from neuroendocrine neoplasms of foregut, midgut, hindgut, and unknown primary. Neuroendocrinology 2012;95: 157-176.

196 Arnold R, Rinke A, Klose KJ, Muller HH, Wied M, Zamzow K, et al: Octreotide versus octreotide plus interferon in endocrine gastroenteropancreatic tumors: a randomized trial. Clin Gastroenterol Hepatol 2005; 3:761-771.

197 Faiss S, Pape UF, Bohmig M, Dorffel Y, Mansmann U, Golder W, et al: International Lanreotide and Interferon Alfa Study Group: prospective, randomized, multicenter trial on the antiproliferative effect of lanreotide, interferon alfa, and their combination for therapy of metastatic neuroendocrine gastroenteropancreatic tumors the International Lanreotide and Interferon Alfa Study Group. J Clin Oncol 2003;21: 2689-2696.

198 Butturini G, Bettini R, Missiaglia E, Mantovani W, Dalai I, Capelli P, et al: Predictive factors of efficacy of the somatostatin ana- logue octreotide as first-line therapy for advanced pancreatic endocrine carcinoma. Endocr Relat Cancer 2006;13:1213-1221.

199 Delaunoit T, Ducreux M, Boige V, Dromain C, Sabourin JC, Duvillard P, et al: The doxorubicin-streptozotocin combination for the treatment of advanced well-differentiated pancreatic endocrine carcinoma; a judicious option? Eur J Cancer 2004;40: 515-520.

200 Fjallskog ML, Janson ET, Falkmer UG, Vatn MH, Oberg KE, Eriksson BK: Treatment with combined streptozotocin and liposomal doxorubicin in metastatic endocrine pancreatic tumors. Neuroendocrinology 2008;88:53-58.

201 Kouvaraki MA, Ajani JA, Hoff P, Wolff R, Evans DB, Lozano R, Yao J: Fluorouracil, doxorubicin, and streptozocin in the treatment of patients with locally advanced and metastatic pancreatic endocrine carcinomas. J Clin Oncol 2004;22 4762-4771.

202 Moertel CG, Lefkopoulo M, Lipsitz S, Hahn RG, Klaassen D: Streptozocin-doxorubicin, streptozocin-fluorouracil or chlorozotocin in the treatment of advanced islet-cell carcinoma. N Engl J Med 1992;326:519-523.

203 Walter T, Bruneton D, Cassier PA, et al: Evaluation of the combination 5-fluorouracil, dacarbazine, and epirubicin in patients with advanced well-differentiated neuroendocrine tumors. Clin Colorectal Cancer 2010;9:248-254.

204 Strosberg JR, Fine RL, Choi J, et al: Firstline chemotherapy with capecitabine and temozolomide in patients with metastatic pancreatic endocrine carcinomas. Cancer 2011;117:268-275.

205 Auernhammer CJ, Goke B: Therapeutic strategies for advanced neuroendocrine carcinomas of jejunum/ileum and pancreatic origin. Gut 2011;60:1009-1021.

206 Vogl TJ, Naguib NN, Zangos S, et al: Liver metastases of neuroendocrine carcinomas: interventional treatment via transarterial embolization, chemoembolization and thermal ablation. Eur J Radiol 2009;72:517-528.

207 Nazario J, Gupta S: Transarterial liver-directed therapies of neuroendocrine hepatic metastases. Semin Oncol 2010;37:118-126.

208 Kwekkeboom DJ, de Herder WW, van Eijck $\mathrm{CH}$, Kam BL, van Essen M, Teunissen JJ, Krenning EP: Peptide receptor radionuclide therapy in patients with gastroenteropancreatic neuroendocrine tumors. Semin Nucl Med 2010;40:78-88.

209 Kwekkeboom DJ, de Herder WW, Kam BL, van Eijck CH, van Essen M, Kooij PP, et al: Treatment with the radiolabeled somatostatin analog $\left[{ }^{177} \mathrm{Lu}-\mathrm{DOTA}^{0}, \mathrm{Tyr}^{3}\right]$ octreotate: toxicity, efficacy, and survival. J Clin Oncol 2008;26:2124-2130.

-210 Bushnell DL Jr, O’Dorisio TM, O’Dorisio MS, Menda Y, Hicks RJ, Van Cutsem E, et al: ${ }^{90}$ Y-edotreotide for metastatic carcinoid refractory to octreotide. J Clin Oncol 2010; 28:1652-1659.
211 Yao JC, Shah MH, Ito T, Bohas CL, Wolin EM, Van Cutsem E, et al: Everolimus for advanced pancreatic neuroendocrine tumors. N Engl J Med 2011;364:514-523.

212 Plockinger U, Wiedenmann B: Management of metastatic endocrine tumours. Best Pract Res Clin Gastroenterol 2005;19: 553-576.

213 Khasraw M, Gill A, Harrington T, et al: Management of advanced neuroendocrine tumors with hepatic metastasis. J Clin Gastroenterol 2009;43:838-847.

214 Shah T, Caplin M: Biotherapy for metastatic endocrine tumours. Best Pract Res Clin Gastroenterol 2005;19:617-636.

215 Teunissen JJ, Kwekkeboom DJ, de Jong M, et al: Peptide receptor radionuclide therapy. Best Pract Res Clin Gastroenterol 2005;19: 595-616.

216 Toumpanakis C, Meyer T, Caplin ME: Cytotoxic treatment including embolization/ chemoembolization for neuroendocrine tumours. Best Pract Res Clin Endocrinol Metab 2007;21:131-144.

217 Eriksson J, Stalberg P, Nilsson A, et al: Surgery and radiofrequency ablation for treatment of liver metastases from midgut and foregut carcinoids and endocrine pancreatic tumors. World J Surg 2008;32:930-938.

218 King J, Quinn R, Glenn DM, et al: Radioembolization with selective internal radiation microspheres for neuroendocrine liver metastases. Cancer 2008;113:921-929.

219 Oberg KE, Reubi JC, Kwekkeboom DJ, et al: Role of somatostatins in gastroenteropancreatic neuroendocrine tumor development and therapy. Gastroenterology 2010; 139:742-753, 753.e1.

220 Kwekkeboom DJ, Krenning EP, Lebtahi R, Komminoth P, Kos-Kudła B, de Herder $\mathrm{WW}$, et al: ENETS consensus guidelines for the standards of care in neuroendocrine tumors: peptide receptor radionuclide therapy with radiolabeled somatostatin analogs. Neuroendocrinology 2009;90:220-226.

221 Arnold R, Chen YJ, Costa F, et al: ENETS consensus guidelines for the standards of care in neuroendocrine tumors: follow-up and documentation. Neuroendocrinology 2009;90:227-233.

222 Poitras P, Gingras MH, Rehfeld JF: The Zollinger-Ellison syndrome: dangers and consequences of interrupting antisecretory treatment. Clin Gastroenterol Hepatol 2012;10:199-202.

-223 Raymond E, Dahan L, Raoul, JL, Bang YJ, Borbath I, Lombard-Bohas C, Valle J, Metrakos P, Smith D, Vinik A, Chen JS, Hörsch D, Hammel P, Wiedenmann B, Van Cutsem E, Patyna S, Lu DR, Blanckmeister C, Chao R, Ruszniewski P: Sunitinib Malate for the treatment of pancreatic neuroendocrine tumors. N Engl J Med 2011;364:501-513.

224 Jensen RT, Delle Fave G: Promising advances in the treatment of malignant pancreatic endocrine tumors. N Engl J Med 2011;364: 564-565. 